NBER WORKING PAPER SERIES

MACRO-ECONOMIC EQUILIBRIUM

AND CREDIT RATIONING

Joseph E. Stiglitz

Andrew Weiss

Working Paper No. 2164

NATIONAL BUREAU OF ECONOMIC RESEARCH

1050 Massachusetts Avenue

Cambridge, MA 02138

February 1987

The research reported here is part of the NBER's research program in Economic Fluctuations. Any opinions expressed are those of the authors and not those of the National Bureau of Economic Research. 


\section{$\underline{\text { ABSTRACT }}$}

In this paper we investigate the macro-economic equilibria of an econony in which credit contracts have both adverse selection and incentive effects. The terms of credit contracts include both an interest rate and a collateral requirement. We show that in this richer model all types of borrowers may be rationed. Interest rates charged borrowers may wove either pro or counter-cyclically. If pro-cyclical shocks have a greater effect on the success probabilities of risky techniques than on safe ones, then the interest rate offered depositors may also move counter-cyclically. Finally, we show that the impact of monetary policy on the macro-economic equilibrium is affected by whether or not the economy is in a regime in which credit is rationed.

Joseph E. Stiglitz

Department of Economics

Dickinson Hall

Princeton University

Princeton, NJ 08544
Andrew Weiss

$2 A-351$

Bell Communications Research 435 South Street

Morristown, NJ 07960-1961 


\title{
Macro-economic Equilibrium and Credit \\ Rationing
}

\author{
J.E. Stiglitz and A. Weiss*
}

\section{Introduction}

In two earlier studies published in this Review, we developed a theory of credit rationing. In our first study, we argued that banks might not increase the interest rate they charged even in the face of an excess demand for funds, for to do so might reduce their expected rate of return. Two reasons were presented for the possible inverse relationship between the rate of interest charged and the expected return to the bank: at higher interest rates, the proportion of high risk borrowers is increased (the adverse selection effect); and at higher interest rates, each borrower has an incentive to use riskier techniques (the moral hazard effect). In our second study, we showed that a bank's commitment to cut off credit to borrowers who performed badly has positive incentive effects.

Rationing might occur whether the banking system was competitive or monopolistic. A profit maximizing monopoly bank might not charge the interest rate at which, at the level of loans it decided to put forth, the demand for loans equals the supply. Similarly, though there will, in general, exist a Walrasian equilibrium, an interest rate at which the competitively determined demand for loans equals the supply, this is not a competitive equilibrium: no bank is forced to charge the "Walrasian" interest rate. We showed that it may pay lenders (banks) to lower the interest rate charged borrowers below the Walrasian level, even though in doing so an excess demand for funds is created.

We developed our theory as a market explanation of the widely observed phenomenon of credit rationing. (As in so many areas in economics, there is 
not universal agreement about the extent or importance of the phenomenon. We did not then, and do not now wish to engage in a debate over the empirical evidence). Our theory did not require recourse to explanations based on institutional considerations or government regulations. Moreover, our theory provided a simple, and we think convincing, explanation of certain practices found in credit markets, such as red lining.

In writing our papers, we attempted to present the simplest models generating credit rationing that we thought provided the basic insights into the phenomena under study. Thought experiments with alternative versions of the model had convinced us that our results were robust, and we thought it would be apparent to the reader how they could be generalized in a number of different directions.

Since then, two important sets of criticisms have been levied against our theory. The first is that if the bank has available to itself instruments by which it could increase its return and which, at the same time, would reduce the demand for its funds, it would use these other (sometimes referred to as non-price) instruments in conjunction with price (interest rate) instruments to eliminate rationing. It is important to remember, in assessing this criticism, that we did not contend that there would always be credit rationing, only that there may be (under not implausible circumstances). Thus constructing an example in which credit rationing does not occur (as several papers have done) should hardly be viewed as a criticism of our theory.

The second criticism is that the result that, within a group of otherwise identical individuals, some would receive credit and others would not, was not robust. In our 1981 paper, we pointed out that if there were several different risk categories, some would be completely denied access to credit; others would not be rationed. Only for one group was it true that some 
received credit while others did not. Hence, given the special assumptions of that model, as the number of groups in the economy increased, the extent of this form of credit rationing decreased.

This criticism seemed important, because we would expect that in most credit markets borrowers can be partitioned into many observationally distinguishable groups. It does not require a deep theory to suggest that no bank would lend to any groups from whom at any interest rate the expected return was zero. 1 It is, however, not so obvious that there are groups for which there is no interest rate at which loans can profitably be made, especially since the expected gross return from projects undertaken by these groups may exceed the expected grose return from projects undertaken by groups that are getting loans; see Stiglitz-Weiss 1981, section IV.

It is true that in our 1981 paper as the number of groups increases, holding the population constant, the number of excluded loan applicants that are identical to borrowers who are getting loans goes to zero. However, there may be a large group of similar loan applicants, some of whom obtain credit and some do not. The sharp discontinuity in utility between those identical borrowers who obtain credit and those who do not is simply translated into a sharp discontinuity in utility between those similar borrowers who do obtain credit and those who do not.

In this paper we make a stronger response to these criticisms. We construct a simple model in which banks can (and do) use both collateral requirements and interest rates to affect both the mix of applicants and the incentives of successful loans appliants. Nevertheless, credit rationing occurs, and indeed, every risk class of borrowing may be rationed, and rationing may occur at every contract. The model we construct has several other interesting features: there may exist pooling equilibria, i.e. equilibria in 
which high risk and low risk individuals borrow at the same terms (in contrast with standard adverse selection models, in which, as Rothschild and Stiglitz established, such equilibria cannot exist). While most studies to date have analyzed moral hazard and adverse selection problems in isolation, we show here how they can be combined, and that the interaction between moral hazard and adverse selection effects may have important consequences.

Perhaps the most important feature of our model is its implications for macro-economic policy and cyclical movements in real interest rates. In particular we show that an expansionary monetary policy can be accompanied by a rise in the average interest rate charged borrowers. Indeed a wide variety of patterns of movements in real interest rates charged borrowers and paid depositors and in the extent of credit rationing are consistent with plausible hypothesis concerning cyclical movements in the returns to various kinds of projects.

\section{Credit Rationing and Collateral}

In our earlier study, we were quite concerned with the use of non-price instruments to eliminate credit rationing. We briefly explored several such instruments, the availability and terms of future contracts, equity finance, loan size and collateral. In this paper, we focus on the interactions between interest rates and collateral requirements.

Increasing collateral requirements makes borrowers less willing to take risks, which increases the return to the bank. On the other hand, increasing collateral requirements may adversely affect the mix of applicants. In our [1981] study we adduced several reasons for this. We showed that even if all individuals had the same utility functions and the same opportunity sets, wealthier individuals--those willing to put up more collateral--would undertake riskier projects than would less wealthy individuals if there was decreasing 
absolute risk aversion. Subsequently, Wette showed that if opportunity sets differ across borrowers, not even the assumption of risk aversion was required. We also suggested that if large wealth accumulations were the results of risk-taking plus luck, a disproportionately large fraction of the very wealthy--those who would put up a large amount of collateral--would be those who were risk loving (or at least not very risk averse): those who had gambled and won.

These negative adverse selection effects may dominate the positive incentive effects. Banks would then find that by increasing their collateral requirements beyond some point, returns would actually be decreased.

The paper is divided into three parts. In Part I. we present the basic analytics of the model. Part II. describes the market equilibrium, while Part III. traces out the macro-economic implications.

\section{Part I. Basic Analytics}

This part is divided into two sections. In the first, we present the basic model. In the second, as a prelude to Part II's fuller analysis of market equilibrium with adverse selection and moral hazard, we analyze market equilibria in which there is only a moral hazard problem.

\section{The Basic Model.}

Since our objectives are to construct a model of the credit market with adverse selection and moral hazard effects, to show how prices and quantities can both be used to convey information and still have credit rationing result, and to examine some of the macro-economic consequences of such a model, we construct the simplest such model, rather than the most general.

We assume that the representative borrower has two possible techniques, a safe one and a risky one, denoted by superscripts $s$ and $r$, 
respectively. A project either is successful, yielding a return of $R^{S}$ or $R^{r}$; or is unsuccessful in which case it has a return of zero.

The probability of success for the safe technique is $p^{s}$, for the risky technique $p^{r}<p^{s}$. We assume $p^{r} R^{r}<p^{s} R^{s}$. Each project costs $\$ 1$ unit and this is more than the wealth of any borrower. Each borrower can undertake at most one project.

The borrower has an initial wealth of $w_{0}$; this is of two forms: collaterizable wealth, $\mathrm{C}_{0}$ and non-collateralizable wealth $\mathrm{H}_{0}$. The latter includes pensions, potential inheritances, and human capital. Wealth not invested in the project yields a safe return of $i^{*}$. The bank requires the borrower to put up collateral $\vec{c}$, and to pay interest on its loan of $r$. (Alternatively, the bank could require the borrower to invest in the project. None of the results derived below would change if the bank required the borrower to put up some of his liquid assets as equity.) Thus, if the project is successful, the end-of-period wealth of the borrower is ${ }^{2}$

$$
Y_{1}=W+R-(1+r)
$$

while if it is unsuccessful, the end of period wealth is

$$
Y_{0}=w-c
$$

where

$$
w=w_{0}\left(1+i^{*}\right), c=\dot{c}\left(1+i^{*}\right)
$$

The expected utility of a borrower is thus

$$
E\{U\}=U\left(Y_{1}\right) p+U\left(Y_{0}\right)(1-p)
$$

where we assume the borrower is risk averse, i.e. 


$$
\mathbf{U}^{\prime}>0, \mathbf{U}^{\prime \prime}<0
$$

It is clear that, if the borrower had no choice of technique (say he could only use technique $\mathbf{r}$ ), then his indifference curve between collateral and interest would be quasi-concave, as depicted in figure 1 . If the borrower could only use technique $s$, his indifference curve would also be quasi-concave, but the indifference curve through any point would be flatter. The reduction in interest rate required to compensate the individual for an increase in collateral is smaller, since the probability of losing the collateral (the probability of a default) is smaller. The slope of the indifference curve is just

$$
\frac{d \mathbf{r}}{d C_{\bar{U}}}=-\frac{U_{0}^{\prime}(1-p)}{U_{1}^{\prime} p}
$$

where $U_{i}^{\prime} \equiv U^{\prime}\left(Y_{i}\right)=\frac{d U\left(Y_{i}\right)}{d Y_{i}}, i=0,1$.

The borrower will choose technique $s$ or $r$, depending on which gives him the higher expected utility. The borrower is indifferent between the two along the locus defined by

$$
E U^{r}=U\left(Y_{1}^{r}\right) p^{r}+U\left(Y_{0}\right)\left(1-p^{r}\right)=U\left(Y_{1}^{s}\right) P^{s}+U\left(Y_{0}\right)\left(1-p^{s}\right)=E U^{s}
$$

where $Y_{1}^{r}$ denotes the end of period wealth of a borrower, who uses the risky technqiue and is successful; $Y_{1}^{s}$ is defined similarly. We note that $Y_{0}$, end of period wealth if the project is unsuccessful, does not depend on the technique used. The locus of $(C, r)$ combinations satisfying ( 3 ) is called the switch line.

\section{INSERT FIGURE I HERE}

For simplicity, assume that a borrower who is indifferent among several 
techniques chooses the safest one. The switch line is positively sloped:

$$
\left.\frac{d r}{d c}\right|_{E U^{r}=E U^{s}}=\frac{U^{\prime}\left(Y_{0}\right)\left(p^{s}-p^{r}\right)}{U^{\prime}\left(Y_{1}^{s}\right) p^{s}-U^{\prime}\left(Y_{1}^{r}\right) p^{r}}>0 .
$$

Above the switch line the borrower undertakes the risky technique; on the switch line and below it where interest rates are low and collateral requirements are high, the borrower uses the safe technique. 3,4 Thus, even though the bank cannot directly control the technique used by the investor, it can indirectly control it: the bank knows precisely the technique that will be used if it offers any particular contract (C, $r)$.

Note that the indifference curves of the individual--taking into account the changes in technique choices which occur as $c$ and $r$ change--

\section{INSERT FIGURE 2 HERE}

are neither quasi-concave nor differentiable. They appear as in figure 2, with the indifference curve above the switch line being discretely steeper below it, reflecting the higher probability of failure. (Recal] from (2) that the slope of the indifference curve depends on the ratio of the probability of failure to the probability of success and on the ratio of $U_{0}^{\prime}$ to $U_{1}^{\prime}$, both of which change discretely, and in the same direction, at the switch line.)

Banks are assumed to be risk neutral. The expected return to the bank, denoted by $\nu$, is

$$
\nu=p^{i}(1+r)+\left(1-p^{i}\right) c
$$

where $p^{i}$ is the probability of success of the project undertaken. For a given project, the iso-return curve is a straight line. At the switch 
line, however, there is a discontinuity in it, as depicted in figure 3.4 INSERT FIGURE 3 HERE

Regardless of whether the individual uses the safe or the risky technique the borrower's indifference curve is steeper than the bank's iso-return locus, because the borrower is risk averse. 5,6

\subsection{Bquilibriun with noral hazard: identical borrowers}

At any interest rate and collateral combination, there will be some level of demand for loans and supply of funds. Assume that at the current interest rate, collateral combination there is an excess demand for funds. Conventional theory would have it that the interest rate would be bid up (or collateral requirements lowered). This is true, until the contract reaches a point which would induce borrowers to switch to the risky technique. Then, the bank simultaneously increases the collateral requirements and interest rate, moving along the switch line, until either demand equals supply, or until $\mathrm{C}=\mathrm{C}_{0}$, the maximum feasible collateral.

Proposition 1 . At $C_{0}$ and at $\dot{r}(C)$, the highest interest rate at which borrowers use the safe technique when $c=c_{0}$, there may still be an excess demand for funds: there may be credit rationing even though the bank is choosing $C$ and $r$ simultaneously.

\subsection{Moral hazard with two groups: No adverse selection.}

Assume now there are two types of individuals who differ only in their wealth. Denoting the rich with subscript $r$ and the poor with a subscript $p$, we assume

$$
w_{p}<w_{r}, c_{p}<c_{r} .
$$


We first assume that banks can tell who is of which type, so there is no adverse selection problem. (We treat the more general case, where there is both an adverse selection and a moral hazard problem, in Parts II and III). The wealthier borrowers will act in a less risk averse manner, provided there is decreasing absolute risk aversion. In this context, that implies that the switch line for the rich lies everywhere below the switch line of the poor. Thus, in Figure 4, we identify three regions: for contracts in region $X$, both the rich and poor use the risky technique; in region $Z$ both use the safe one; in region $Y$, the poor use the safe technique and the rich the risky technique.

\section{INSERT FIGURE 4 HERE}

For future reference, we record one further aspect of the comparison of the rich and the poor, the indifference curve of the rich through any point in the region $x$ or $Z$ (where they both use the same technique) is always flatter than that of the poor; they need less of a reduction in interest charges to compensate them for any increase in collateral, given that they use the same technique. But in region $Y$, where the rich use the riskier technique and the poor the safer one, the indifference curve of the rich may be steeper or flatter than that of the poor. 7

\section{INSERT FIGURES 5,6 HERE}

We denote by contract $\{F\}$ the contract with $\mathrm{C}=\mathrm{C}_{\mathrm{p}}$ and the highest interest rate, consistent with the poor using the safe technique. Contract $\{G\}$ is the contract with $C=C_{r}$ and the highest 
interest rate consistent with the rich using the safe technique.

(See figures 5 and 6.) We denote by $\nu_{x}\{K\}$ the expected return to the bank from contract $K$ when a fraction $x$ of those taking it are poor:

$\nu$ is the expected return when only the poor take it. 8 In the obvious
notation, $\nu_{1}\{K\}=\nu_{p}\{K)$ and $\nu_{0}\{K\}=\nu_{r}\{K\}$.

Since only rich borrowers can choose contract $\{G\}$ we shall write $\nu_{0}(G)$ as $\nu(G)$. It is apparent that $\nu_{p}(F)$ may be either greater or less than $\nu(G)$. The collateral requirement is higher at $G$ than at $F$ and this increases the bank's expected return; but the interest rate may be lower (because the rich borrower's switch line lies below that of the poor) .9

The equilibrium may take on any of 5 forms: (i) Only the rich obtain credit, and they are rationed; (ii) Only the poor obtain credit and they are rationed; (iii). Both the rich and the poor obtain credit but only the rich are rationed; (iv) Both the rich and the poor obtain credit, but only the poor are rationed; (v) Both the rich and the poor obtain credit, and neither are rationed.

We let $N_{r}$ and $N_{p}$ denote the number of $r i c h$ and poor potential investors; $N=N_{p}+N_{r}$, and $z=\frac{N_{p}}{N}$. Let $L(i)$ be the supply of funds, where $i$ is the real expected return to depositors (for simplicity, depositors are assumed to be risk neutral); $L^{\prime}(i)>0$ : the supply of funds increases with $i$. Competitive equilibrium in the banking industry implies that if the poor and rich both obtain loans, and have different contracts, the two contracts must yield the same return, and the return must be equal to $i$. Denoting the equilibrium contract for the rich by $E_{r}$ and for the poor by $E_{p}$, we then have 


$$
i=\nu_{r}\left\{E_{r}\right\}=\nu_{p}\left\{E_{p}\right\}
$$

Thus, if the maximum return obtainable frow the rich, ${ }^{\nu}\{G\}$, exceeds the maximum return obtainable from the poor $\left[\nu_{p}\{F\}\right]$, and if at $i=\nu_{r}\{G\}$, the supply of funds is less than the demand by the rich, then only the rich will obtain loans, and not all of them will; banks will not increase the interest rate, for to do so, would induce the rich to undertake the risky project, lowering the bank's return. By the same token, if the maximum return obtainable from the poor exceeds that from rich, and the supply of funds at that return is less than total demand by the poor, then only the poor will get funds. The contract offered will be $F$ and there will be rationing.

When the return at $G$ exceeds that at $F$, but the demand for funds by the rich is less than the supply forthcoming at $i=\nu_{r}\{G\}$, then both the rich and poor will obtain funds. There may, however, be rationing of the poor. If there is rationing of the poor, the contract offered the poor must be $F$. Hence, by (7), the contract offered to the rich, which we denote by $H$, must be the contract that maximizes the rich borrower's utility subject to the constraint that $\nu_{r}\{H\}=\nu_{p}\{F\}$. In Figure 7 $H$ is given by the intersection of an iso-return line through $F$ (for loans to finance the safe technique) with the rich individual's switch line. This iso-return line has slope $-\left(1-p^{3}\right) / p^{3}$.

\section{INSERT FIGURE 7 HERE}

The other cases may be analyzed in a similar way. We can sumarize our findings in the following Proposition 2. If there are two for more groups in the population, with differing collateralizable weath and if the bank can ascertain to which group each 
borrower belongs, then the contracts offered different groups will differ. Some groups may be excluded from the market; other groups will not be excluded; and there may exist some group some of whose members obtain loans and other do not. This group is referred to as the rationed group. Tightening of credit (a reduction in the supply of funds) will be reflected first in a reduction of loans made to the rationed group, until that group is entirely rationed out of the market; then in an increase in collateral requirements and interest rates charged non-rationed groups; then in rationing being imposed on one of the groups that was formerly not rationed. 10

Note that it may be either the higher or lower interest rate contracts which are rationed, and hence, a reduction in the supply of available funds may either increase or decrease the average interest rate charged borrowers.

\section{Part II. Equilibrium with Adverse Selection and Moral Hazard}

We now assume that the banks know that there are poor and rich borrowers, but cannot ascertain who is of which type. There is, in other words, both an adverse selection and a moral hazard problem. The choice of contracts may, however, reveal information about who is of which type. Clearly, any borrower applying for a contract with collateral requirements in excess of $C_{p}$ must be rich. There may again exist equilibria with or without rationing. We focus on the former.

The rationing equilibria in this economy may be characterized by complete pooling (rich and poor borrowers receiving the same contract) or by separating (at least some of the rich borrowers receiving loans at different contract terms from those received by the poor borrowers). Although we allow each bank to offer several different contracts, the 
equilibria we construct have the characteristic that each bank only offers one contract. 11

We assume that after each bank offers a contract(s), borrowers apply for loans at every bank offering a contract that would increase the borrowers' utility relative to not getting credit. (There is no cost of application but a borrower cannot apply for a loan contract that requires more collateral than the borrower has.) Each bank observes the contracts offered by the other banks, and makes some inference concerning its expected return from each contract it is offering. From this inference the bank determines the number of loans it will make at each contract that it offered. Borrowers accept the contract they are offered that gives them the highest expected utility. (If a borrower is indifferent among several contracts it chooses each with equal probability.) Finally, borrowers who have obtained loans make their investment decisions. Loan applicants who have been denied credit may deposit some or all of their liquid funds in banks. The interest rate paid depositors is such that the aggregate supply of funds is equal to the contracted quantity of loans. We assume that banks are small so that no single bank can affect i. 12

This part is divided into three sections. In the first, we analyse the pooling equilibrium; in the second, a partial separating equilibrium, while the final section discusses some extensions of analysis.

\section{A Pure pooling equilibriu with rationing}

The first rationing equilibrium we shall consider is a complete pooling equilibrium. We first show that if there is a pure pooling equilibrium with with rationing, it must be at $\{F\}$, the contract requiring $C_{p}$ of collateral, and offering the highest interest rate at which the poor 
borrowers invest in the safe project. We shall assume that profits (per dollar loaned) at $F$ when the fraction of the poor equals or exceeds $z$ are higher than at any contract where the poor use the risky technique. Hence, we can exclude every contract in region $X$ of Figure 3 from being a pooling equilibrium with rationing. Since $\{F\}$ generates higher profits than (other) contracts in region $Y$, those contracts also can be excluded as candidates for pooling equilibria with rationing. Finally no contract in region $Z$ can be a pooling equilibria with rationing because contract $\{G\}$ generates strictly greater profits than do those contracts. Thus rationed borrowers would be offered contract $\{G$ \} and the bank making that offer would make positive profits.

In the pooling equilibrium, $i=\nu_{z}\{F\}$, and the supply of funds is thus $L\left(\nu_{z}\{F\}\right)$. Contract $\{F\}$ is a rationing equilibrium if $\nu_{z}(F)>\nu(G)$, and $L\left(v_{z}(F)\right)<N$. To show that "all banks offering $F$ " is a rationing equilibrium, let us first consider a deviation from (F) by some banks offering only a single contract other than $\{F\}$. There is no contract that would attract only poor borrowers and would induce those poor borrowers to use the safe technique. Thus, any contract requiring $\mathrm{C}_{\mathrm{p}}$ or less of collateral would generate a return less than $\nu_{z}\{F\}$. From the definition of $G$, any contract requiring more than $C_{p}$ of generates a return less than or equal to $\nu\{G\}$ which is less than $\nu_{z}(F)$. Consequently, since credit is being rationed, those contracts would not be offered.

Let us now consider a bank deviating from this equilibrium by offering several contracts. We shall assume that a bank can costlessly learn which of of its contracts a borrower applied for and that this learning ability is 
common knowledge. It offers several contracts in order to better distinguish among applicants. A bank would deviate from offering $\{F\}$ if it anticipated making positive profits by doing so. In that case at least one of the contracts must attract a proportion of poor borrowers greater than $z$, which implies that some other contract attracts a proportion of poor borrowers that is less than 2.13 This latter contract would generate a return to the bank that is less than $\nu_{z}\{F\}$. Since the interest rate paid depositors is $i=\nu_{z}\{F\}$, those contracts would generate losses to the deviating bank and hence would not be funded. Borrowers know that the bank knows for which contracts a borrower applied, and will use that knowledge to infer whether a borrower is rich or poor. Hence, by applying for the contract that is designed to attract a high proportion of rich borrowers, borrowers will anticipate being labeled rich and hence being denied credit at the other contract(s) designed to attract the poor borrowers. Since any contract(s) designed to attract the rich will not be funded, no borrowers will apply for them. This argument will iteratively eliminate all but one contract. Consequently, offering a contract pair is equivalent to offering only a single contract, and as we have shown "all banks offering contract F" is an equilibrium in this economy when banks can only offer a single contract. 14

\section{A partial pooling-partial separating equilibriu with rationing}

There are also rationing equibria in which some of the rich and poor borrowers borrow at the same terms, while some rich borrowers accept contracts that are not chosen by any poor borrowers.

Suppose:

i) the rich borrowers prefer contract $\{G\}$ to contract $\{F\}$,

ii) $\nu_{z}(F)<\nu(G)<\nu_{1}(F)$

iii) $L(\nu(G))<N$. 
There is a rationing equilibrium in which contracts $\{F\}$ and $\{G\}$ are offered. All the rich borrowers apply for loans at every bank offering either contract $\{G\}$ or $\{F\}$. A rich borrower only accepts a contract $\{F\}$ offer if he is not offered a $\{G\}$ loan. In equilibrium, the number of rich borrowers getting $G$ loans, $N_{G}$, is such that the proportion of poor borrowers, $x$, among those accepting $\{F\}$ loans satisfies $\nu_{x}(F)=\nu(G)$. (By continuity and (ii) there always exists a value of $x$ satisfying this condition.) The number of $F$ loans made, $N_{F}$, is such that

$$
L(\nu(G))=N_{G}+N_{F} .
$$

If $L(\nu(G))>N_{G}, N_{F}>0$, both $\{G\}$ and $\{F\}$ are offered, and rationed; while if $L(N(G))<N_{G}$, only $\{G\}$ is offered.

The reader can easily verify that when no loans are made at $\{G\}$ any single contract other than $\{G\}$ or $\{F\}$ generates a return strictly below $\nu(G)$. From the argument given above, for any bank offering several contracts, at least one of those contracts will generate a return below $\nu(G)$ and will not be funded so that the "several contract strategy" again degenerates into a single contract.

Note that while both rich and poor borrowers are rationed the rich borrowers are more likely to get loans than are the poor borrowers. The qualitative features of this equilibrium are quite general.

Note that this analysis differs from the earlier Rothschild-Stiglitz-Wilson analysis in in four fundamental ways. First, we have both adverse selection and moral hazard effects. Secondly, the indifference curves do not satisfy the single crossing property (a condition which seemed natural in the context of the problems that they atudied, but is not naturally satisfied here). Thirdly, they did not admit (and their analysis did not require) the possibility 
of rationing; here we do. Fourthly, and as a natural consequence of the presence of rationing, our equilibrium concept differs. The possibility--indeed necessity--of the uninformed (the bank) turning down applications, and of the informed (the borrower) turning down acceptances leads to an equilibrium which is similar to the reaction equilibrium analyzed by Wilson (1977). 15,16

Note that while a pooling equilibrium requires the rich to prefer $\{F\}$ to (G) , the partially separating equilibrium requires that they prefer [G] to \{F\}. Figure 8 illustrates the two possibilities.

\section{INSERT FIGURE 8 HERE}

A natural question is whether the inequalities $\nu_{1}\{F\}>\nu_{0}\{G\}>\nu_{z}\{F\}$ and $\operatorname{EU}^{\mathrm{r}}\{G\} \geqslant \mathrm{EU}^{\mathrm{r}}\{\mathrm{F}\}$ can be satisfied simultaneously. We know that with constant absolute risk aversion, the switch lines coincide; hence $\operatorname{EU}^{\mathrm{r}}\{G\} \leqslant \operatorname{EU}^{\mathrm{r}}\{F\}$. With (sufficiently) decreasing absolute risk aversion and (sufficiently) large differences in non-collaterizable wealth, the switch line of the poor is moved down relative to the rich enough that both $\nu_{1}\{F\}>\nu_{1}\{G\}$ and $\operatorname{EU}^{r}\{G\}>E^{r}\{F\}$. If $C_{r}$ is not too different from $c_{p}$, the success probability of the risky project is sufficiently less than that of the safe, and the proportion of the rich in the population is sufficiently large, then $\nu_{z}\{F\}<\nu\{G\}$. In figure 9 we depict, for fixed collaterizable and non-collaterizable wealth of the poor and given decreasing absolute risk aversion utility functions the set of collaterizable and non-collaterizable wealth levels of the rich for which there may exist a partially separating equilibrium. 17 


\section{Bxtensions}

There are four obvious extensions to the analysis: we could allow the set of feasible projects to differ across borrowers; we could allow each type of borrower to choose from several or a continuum of techniques, we could allow for more than two types of borrowers, and we could increase the number of instruments available to banks. None of those changes in our model change our fundamental results that there can be both separating and pooling equilibria with rationing, and that in both the pure pooling and partial pooling equilibria all typs of borrowers may be rationed.

\section{Differing Sets of Feasible contracts.}

As we mentioned in the introduction, the first extension, allowing the set of feasible technqiues to differ across borrowers, makes our results easier to obtain. This can be seen by observing that the conditions for a pure pooling equilibrium with rationing are certainly more readily satisfied if the set of techniques available to the poor borrowers stochastically dominates the techniques available to rich borrowers. In that case, a lender would be less likely to increase collateral as a means of eliminating rationing.

\section{Continum of Projects.}

The second extension--allowing each type of borrower to choose from a continuum of projects, rather than just two projects--requires a slight change of notation, but otherwise does not substantially affect our results. In the case of a pure pooling equilibrium, we define $\mathbf{r}^{*}$ as the interest rate at which the bank's expected return per dollar loaned is maximized when it requires $c_{p}$ of collateral on loans to a proportion $z$ of poor borrowers. If the return on contract $\left\{r^{*}, c_{p}\right\}$ 
exceeds the maximum return on a loan to a rich borrower, and there is an excess demand for credit when contract $\left\{r^{*}, c_{p}\right\}$ is offered, then there is pure pooling equilibrium with all banks offering contract $\left\{r^{*}, c_{p}\right\} .18$ Similar arguments can be made for extending our construction of partially separating contracts and completely separating contracts with rationing to the case when a continuum of techniques are available to borrowers.

Many types of borrowers.

The third extension is to allow for several types of borrowers. In the extreme case where there are several types of borrowers, with the same amount of collateralizable wealth $(\bar{C})$ but different non-collateralizable wealth (or who differ in risk aversion for some other reason), we can get credit rationing even without incentive effects. The mix of applicants may still change adversely as we increase $r$, at $c$. If the indifference curves of poor (safe) borrowers are flatter than those those of richer (riskier) borrowers at the "equilibrium" contract, then no contract can be offered that only attracts safe borrowers.

Our model, in which each type of borrower has a different endownent of collateralizable wealth may also be directly extended to the case of many types of borrowers. The analyses of pure pooling and the separating equilibria with rationing follow directly from our analysis with two types. In the pure pooling equilibrium all borrowers again choose contract $\{F\}$.

In the case of a partial pooling equilibrium, we begin with the wealthiest types, and assume that richer borrowers prefer the higher collateral contracts that are offered, in equilibrium and feasible for that borrower. The contract $\left\{G_{1}\right\}$ that maximizes the return for loans the wealthiest borrowers determines the return $\nu\left(G_{1}\right)$ for all other loans. The proportion of the wealthiest borrowers that get loans 
at contract $\left\{G_{1}\right\}$ is just sufficient to ensure that the bank's maximum expected return on loans at a contract requiring collateral equal to the collateralizable wealth of the next wealthiest borrowers is equal to $\nu\left(G_{1}\right)$. Denoting that contract by $\left\{G_{2}\right\}$, the proportion of applicants getting loans at contract $\left\{G_{2}\right\}$ is such that the maximum return from loans at a contract requiring collateral equal to the collateralizable wealth of the third wealthiest borrowers is also equal to $\nu\left\{G_{1}\right\}$. This process continues through all types. It is easy to specify a supply of loanable funds and return functions for different types of borrowers that will generate rationing of each type of borrower.

\section{Additional instruments.}

Collateral is just one of the instruments by which banks attempt to select among applicants and to provide incentives for borrowers to undertake safer projects. Other instruments face similar problems in combining conflicting incentive/selection effects, or in any case, are sufficiently, ineffective as to leave a residual incentive/selection problem of the kind with which we have been concerned here.

Consider for instance the effect on our analysis from allowing banks to demand equity from borrowers as well as collateral, by providing smaller loans. If providing more equity reduces the amount of collateral a borrower can provide, this additional instrument is redundant. The return to a bank is not affected by the amount of equity participation demanded by the contract. (See Stiglitz-Weiss [1985] for a proof of this result.)

On the other hand, if the rich have some non-collaterizable assets which can be used to finance part of the investment, but the poor have none, increasing equity requirements (reducing the loan size) could have 
strong adverse selection effects. 19

Part III. Macro-Economic Implications

In this part, we explore the macro-economic implications of credit rationing. We address ourselves to three questions: (a) what are the consequences of a shift in returns to different projects, such as might occur over the business cycle? (section 8); (b) what are the consequences of a shift in the supply of funds (section 9); and (c) what implications does the fact that there is credit rationing have for monetary policy? (section 10). Throughout the analysis, we assume a simple, general equilibrium version of the model presented in the previous two sections. Thus, there are two types of borrowers, each of whom has two types of projects. Traditional macro-economic analysis has made extensive use of the concept of the "representative" firm and the representative consumer. We would argue that such models cannot adequately address those macroeconomic problems which arise from imperfect information (where heterogeneity is central). The models we present here represent the simplest ones within which such problems can be addressed.

8. Effects of Changes in Productivity. Business Cycles are marked by large cyclical fluctuations in the likelihood of success of various projects. This is reflected, for instance, in the marked cyclicity of bankruptcy rates. What effects do these have on the extent and likelihood of credit rationing? We argue below that our model is consistent with real interest rates charged borrowers rising in recessions, while that paid depositors may fall, and conversely during booms. More generally, our model is consistent with a wide variety of patterns of cyclical movements in interest rates charged, interest rates received and in the degree of rationing.

For analytical purposes, we need to distinguish two cases: 
1. Balanced changes in success probabilities. We first assume that the probability of success of both the safe and the risky techniques of production are changed in the same proportion. For simplicity, we write

$$
\mathbf{p}^{\mathbf{s}} *=\beta \mathrm{p}^{\mathrm{s}}, \mathrm{p}^{\mathrm{r}} *=\beta \mathrm{p}^{\mathrm{r}}, \boldsymbol{\beta}>0 \text {. }
$$

$\beta$ varies procyclically, e.g. $\beta>1$ in a boom, $<1$ in a recession.

Then, rewriting equation (3), describing the switch line,

$$
\left.\left[U\left(Y_{1}^{r}\right)-U\left(Y_{0}\right)\right] p^{r} *=\left[U_{1}\left(Y^{s}\right)\right)-U_{0}(Y)\right] p^{s} *
$$

we immediately see that the switch line is unaffected. It thus follows that if there is a pooling equilibrium, the rate of interest and the collateral requirement will remain unchanged. But since the expected return to the bank (and hence the interest paid to borrowers)

$$
\nu \equiv \hat{p}(1+r)+(1-\hat{p}) C_{p}
$$

(where $\dot{p}=2 p^{s}+(1-z) p^{r}$, the mean probability of success) is increased by an increase in $\beta$, the supply of funds is increased. 20 Hence, if the demand for funds is unchanged, 21 the extent of credit rationing is reduced.

Similarly, if we are in (partially) separating equilibrium, of the form described in section 6 , then the contracts offered will remain unchanged ( $\{F\}$ and $\{G\})$. Since the return at $G$ has increased, the return at $\{F\}$ must have increased. To see what happens to the fraction at $\{F\}$ who are poor, we observe that for $\{F\}$ to equal $\{G\}$,

$$
\begin{aligned}
& \left.\left[\beta p^{s} x+(1-x) \beta p^{r}\right]\left(1+r_{F}\right)+\left(1-\left(\beta p^{s} x+(1-x) \beta p^{r}\right)\right)\right) C_{p}= \\
& \beta p^{r}\left(1+r_{G}\right)+\left(1-\beta p^{r}\right) C_{r},
\end{aligned}
$$

(where $r_{F}$ and $r_{G}$ are the rates of interest in contracts $\{F\}$ and $\{G\}$ respectively), from which it follows that 


$$
\beta \mathrm{dx} / \mathrm{d} \beta=-\left[\mathrm{C}_{\mathrm{r}}-\mathrm{C}_{\mathrm{p}}\right] /\left(\mathrm{p}^{\mathrm{s*}}-\mathrm{p}^{\mathrm{r*}}\right)\left[1+\mathrm{r}_{\mathrm{F}}-\mathrm{C}_{\mathrm{p}}\right)<0,
$$

i.e. when $\beta$ increases a smaller fraction of the rich get loans at contract (G) so that a larger fraction accept contract $\{F\}$. An equi-proportionate increase in success probabilities decreases the value of collateral to the lender. Because G loans demand more collateral than F loans, an increase in $\beta$ has a smaller effect on the profitability of $\{G\}$ loans than of $\{F\}$ loans. If both $F$ and $G$ loans are to continue to be made, the increased profitability of $F$ loans must be offset be an increase in the proportion of rich borrowers choosing $F$ loans, i.e. $x$ must decrease. Since $\nu\{G\}$ is increased, the interest rate paid depositors is increased, and so is the aggregate quantity of loans. Accordingly, both the proportion and absolute number of $G$ loans would fall as banks making $F$ loans are able to compete more aggressively for borrowers. Hence the average interest rate charged and average interest rate paid both increase with $\beta$ (move procyclically).22

2. Unbalanced changes in success probabilities. Asumme now, however, that as the economy goes into a recession, risky projects have a disproportionate increase in their probability of failure, and in a boom, they have a disproportionate increase in their probability of success. Thus, we write

$$
\begin{aligned}
\mathbf{p}^{\mathbf{s}^{*}}= & \delta \beta \mathbf{p}^{\mathrm{s}} ; \mathrm{p}^{\mathrm{r} *}=\beta \mathrm{p}^{\mathrm{r}} \text {, with }(\delta-1)(\beta-1)\langle 0 ;(\delta \beta-1)(\beta-1)>0 ; \\
& \forall \delta, \delta \mathrm{p}^{\mathbf{s}}>\mathrm{p}^{\mathrm{r}} .
\end{aligned}
$$

We ask, what is the effect of an increase in $\delta ?$ A change in $\delta$ shifts the switch line. The equation for the switch line can now be written Thus,

$$
\left[\mathrm{U}\left(\mathrm{Y}_{1}{ }^{\mathrm{r}}\right)-\mathrm{U}\left(\mathrm{Y}_{0}\right)\right] \mathbf{p}^{\mathbf{r}}=\left[\mathrm{U}\left(\mathrm{Y}_{1}^{\mathbf{S}}\right)-\mathrm{U}\left(\mathrm{Y}_{0}\right)\right] \mathbf{p}^{\mathbf{s}_{\delta}} .
$$




$$
{ }^{\mathrm{d} r} /\left.\mathrm{d} \delta\right|_{E U^{r}=E U^{s}}=-\left[U\left(Y_{1}^{s}\right)-U\left(Y_{0}\right)\right] p /\left[E U_{1}^{r} p^{r}-\delta E U_{1}^{s}{ }_{p}^{s}\right]>0
$$

i.e. the switch line shifts down in a boom as the risky project becomes relatively more attractive, up in a recession. Thus, in the pooling equilibrium, provided risky projects exhibit more cyclical volatility than do safe projects, interest rates charged borrowers will move in a counter-cyclical manner.

Even more surprising is the result that for sufficiently "unbalanced" changes in productivity, the interest rate paid depositors may actually fall in a boom. That is, recalling our definition of $\dot{p}$ as the mean probability of success in a pooling equilibrium,

$$
\begin{aligned}
& \beta \frac{\mathrm{d} \nu}{\mathrm{d} \beta}=\left[\dot{\mathrm{p}}+\frac{\partial \ln \delta}{\partial \ln \beta} \mathrm{zp} \mathrm{s}^{*}\right]\left(1+\mathrm{r}_{\mathrm{F}}-\mathrm{C}_{\mathrm{p}}\right)+\dot{\mathrm{p}} \frac{\partial \ln \delta}{\partial \ln \beta} \frac{\mathrm{dr}}{\mathrm{d} \ln \delta}<0 \text {, if } \\
& \left|\frac{\mathrm{d} \ln \delta}{\mathrm{d} \ln \beta}\right|>\frac{1}{\frac{\mathrm{d} \ln \left(1+\mathrm{r}_{\mathrm{F}}\right)}{\mathrm{d} \ln \delta} \frac{1}{1-\mathrm{C}_{\mathrm{p} / 1+\mathrm{r}_{\mathrm{F}}}}+\frac{\mathrm{zp} \mathrm{p}^{\mathrm{s}^{*}}+(1-\mathrm{z}) \mathrm{p}^{\mathrm{r}}}{2 \mathrm{p}^{*}}}
\end{aligned}
$$

where $\frac{d r_{F}}{d \delta}$ is the change in the interest rate at contract $\{F\}$ induced by a change in $\delta$, (given by (10)). When $v$ decreases and $r_{F}$ decreases, the magnitude of credit rationing will clearly increase in a boom.

In the partially separating equilibrium, the interest rates on both contracts $\{F\}$ and $\{G\}$ decrease in a boom. But the decrease in the interest rate at [G] may either exceed or be less than at $\{F\} .23$ As before, the returns at $\{F\}$ and $\{G\}$ are altered, but by differing amounts. Hence, for the return at (F) to equal to the return on [G\}, the fraction 
of loans made at [G] will have to adjust, but it is ambiguous whether it will increase or decrease. Accordingly, although there may be some presumption that the average rate of interest will decrease in a boom, it is possible that if the proportion of the rich getting loans is decreased enough, then the average rate of interest charged borrowers will actually increase.

It should also be clear that it is quite possible that as the economy enters a boom rationing at $\{F\}$ increases. This is particularly striking, given that in these boom times the (social) productivity of the risky technique is high relative to that of safer techniques, and only F loans finance the risky technique.

As before, for sufficiently "unbalanced" changes in productivity, interest rates paid depositors may fall, i.e.

$\beta \frac{\mathrm{d} v}{\mathrm{~d} \beta}=\mathrm{p}^{\mathrm{r} *}\left(1+\mathrm{r}_{\mathrm{G}}-\mathrm{C}_{\mathrm{p}}+\frac{\partial \ln \delta}{\partial \ln \beta} \frac{\mathrm{d} r_{G}}{\mathrm{~d} \ln \delta}\right)<0$

if

$$
\left|\frac{\mathrm{d} \ln \delta}{\mathrm{d} \ln \beta}\right|>\frac{1}{\frac{\mathrm{d} \ln \left(1+\mathrm{r}_{\mathrm{G}}\right)}{\mathrm{d} \ln \delta} \frac{1}{1-\left(\mathrm{C}_{\mathrm{p}} h+\mathrm{r}_{\mathrm{G}}\right)}}
$$

Our discussion in this section has been predicated on the changes in productivity being sufficiently small that there is no change in regime. Of course, with large productivity shocks, the economy may go from a situation where there is credit rationing, to one where there is not, or conversely. 24

Our analysis has also been predicated on the changes in projects being the same for the rich and poor. So long as, for both groups, the risky projects become relatively more attractive in a boom, the interest rates charged on any particular contract will fall, but the mix of contracts may 
change in such a way as to decrease or increase the average interest rate charged or paid.

It is thus apparent that our model is consistent with a variety of patterns of cyclical movements of the extent of credit rationing and interest rates paid and charged. Our model is in particular, consistent with the fact that interest rates are far less volatile than the returns to equity ( $\pi$ ). Interest rate may also be less volatile than they might be with perfect information, 25 and investment more volatile.

9. Changes in the supply of funds.

One of the reasons for our interest in credit rationing is that it raises the possibility that the way that the central bank affects the level of economic activity is not through changes in the interest rate but through changes in credit availability. In this section, we trace out the consequences of an upward shift in the supply of funds.26

We should emphasize that while a reduction in the available funds reduces investments, the projects which are eliminated are not necessarily those with the highest social productivity, i.e. those for which, in our model, pR is highest. In particular, in the pooling equilibrium, the proportion of good projects eliminated is equal to the proportion of bad projects, while in the partially separating equilibrium, it is only the low collateral projects which are eliminated.

As more credit becomes available, the number of projects undertaken increases, but the average interest rate charged may remain unchanged (in the pooling equilibrium) or may actually increase (in the partially separating equilibrium). To see how an increase in the supply of loanable funds could increase the average interest rate charged, observe that as the number of loans increases, if the return on the contracts (F) and [G] is to remain 
the same, the number of loans made at (G) must remain unchanged; at that margin all additional credit goes to the low collateral loans. But the interest rate charged on the low collateral loans must exceed that on the high collateral loans, and hence the average interest rate charged must increase. A full analysis of the effects of a change in the supply of loanable funds is contained in Appendix A.

There we note too that as the supply curve for funds shifts the nature of the equilibrium (rationing at two contracts, rationing at one contract, no rationing, etc.) may change.

10. Monetary policy, macro economic equilibrium, and credit rationing.

A natural question to be raised at this juncture is, how does our analysis affect one's view of the role of monetary policy. There is a sense in which our model conforms closely to traditional views, a sense in which it differs markedly.

In traditional Keynesian analyses, an increase in " $M$ " (money supply) leads to a reduction in interest rates; the reduction in interest rates leads to an increase in investment; and the increase in investment leads to a higher level of income.27 The traditional analysis was based on a stable relationship between money, income and interest rates, and is usually motivated by some transactions story (ignoring, of course, the fact that most transactions in dollar terms, are trades in assets, and there is no a priori reason for a stable relationship between asset transfers and income flows--on the contrary, there are strong a priori reasons that over the business cycle this relationship might change). The traditional analysis also obfuscated which interest rate was relevant, and ignored the fact that, except in certain isolated periods $(1932-35,1980-85)$ real interest rates--which modern economists would argue are the relevant ones--have hardly varied at 
all, and have been negligible relative to the expected returns demanded by firms on their investments.

In our analysis, there are two critical links, between the money supply, "M," and credit availability, A, and between credit availability and investment. Of course, if, as in simpler versions of our model,

$$
\mathrm{A}=\mathbf{a M} \text {, }
$$

the (flow of) available credit (A) is proportional to the money supply, and

$$
\mathrm{I}=\mathrm{Ab} \text {, }
$$

investment $I$ is proportional to the supply of available credit, then, if

$$
\mathrm{Y}=\text { Consumption + Investment + Government expenditure G , }
$$

and

$$
\mathrm{C}=\mathrm{mY}
$$

then

$$
Y=\frac{a b M+G}{1-m},
$$

national income increases with money supply, as in conventional monetary models. This is the sense in which our model is similar to standard models.

But it is equally important to note the differences. First, we would argue that the link between " $M$ " and " $A$ " is likely to change over the business cycle, with an increase in money supply having a relatively weak effect on credit availability in recessionary periods. (For a more extended discussion of the link between $M$ and $A$ see Blinder and Stiglitz (1983) and Greenwald and Stiglitz (1986).)

Secondly, we note that monetary policy can be contractionary (expansionary) even though the average real interest charged borrowers changes little, or indeed decreases (increases). More generally, our model suggests that neither of the intermediate targets often proposed for monetary 
policy--interest rates or money supply--may be closely related to what the government is ultimately interested in, and accordingly these intermediate targets should only be used with caution.

Thirdly, our model explains why monetary policy seems to have such differential effects in different sectors of the economy, 28 and why the interest rate charged borrowers in different sectors may change at different rates, or even in different directions. Our theory predicts that credit rationing may be more important in certain sectors than in others, and indeed a decrease in the availability of credit would be largely felt in a few sectors. Whether one wishes, as a matter of policy, to make those sectors bear the brunt of the required macro-economic adjustments is clearly a subject for debate. 29

Fourthly, our model suggests that monetary policy may have a much larger effect on investment if the economy is in a credit rationing regime than if it is not. 30

Fifthly, one of the reasons that monetary policy has effects when it does is that other forms of credit are, for many borrowers, imperfect substitutes for bank borrowing (because of the differential information of the bank, and the problems associated with transferring information). On the other hand, in the long run, non-bank credit is likely to become a better substitute for bank credit; and to the extent that the government repeatedly uses tight money policies to reduce investment, whatever advantages the banking system has as a credit institution will be decreased; other institutions will arise, and existing institutions will offer better substitutes for bank credit. Thus, monetary policy is effective only if limited use is made of it. This is a conclusion one would not reach within the more traditional Keynesian model. 
There is one final reason that we would argue a macroeconomist should be interested in credit rationing: Conventional expositions of Keynesian analysis often stress the dichotomy between savings and investment, and the fact that while households do the saving, it is firms that do the investment. 31 In the traditional neoclassical model, that dichotomy plays no role: there is no corporate veil. In the presence of informational imperfections of the kind that we have been concerned with here, which lead to credit rationing (or to equity rationing, as in Greenwald and Stiglitz (1986))the dichotomy between households and firms does become important. 32

\section{Concluding Remarks}

In this paper, we have shown that there may be credit rationing, at all contracts offered, even when collateral can, and is, used optimally (in conjunction with the other provisions of the loan contract, in particular, the interest rate charged) to differentiate among borrowers with differing probabilities of default.

The idea that the terms of a loan contact might affect the mix of borrowers (and hence the return to the lender) is, of course, not a new one. More than 200 years ago, Adam Smith wrote that if the interest rate was fixed too high

"...the greater part of the money which was to be lent, would lent to prodigals and profectors. Sober people, who will give for the use of money no more than a part of what they are likely to make by the use of it, would not venture into the competition." 33

But Adam Smith (and subsequent writers) did not attempt to analyze the equilibrium in competitive capital markets, under such circumstances. This has been the major objective of this as well as our previous studies. We have shown that a central consequence is that there may be credit 
rationing. Credit rationing can occur if three conditions are satisfied:

1. There must be some residual uncertainty (Information imperfection), after lenders employ whatever means they have at their disposal to differentiate among applicants and to control their behavior. 34

2. The adverse selection/adverse incentive effects of changing interest rates or the non-price terms of the contract (collateral, equity, etc.) must be sufficiently strong (at some values of the relevant variables) that it is not optimal for the lender to use these instruments fully to allocate credit.

3. The supply of funds must be such that at the Walrasian equilibrium (where demand equals supply, taking into account the use of non-price instruments), the expected returns to the lender are lower than for some other contract, at which there exists credit rationing.

The first condition, we would contend, is virtually always satisfied, but the second and third conditions may or may not be:33 we believe that credit markets are sometimes, but not always, characterized by credit rationing. When credit rationing is observed, it may be caused by other factors (such as legal restraints on the level of interest rates charged). But there are circumstances in which credit rationing occurs at interest rates below legally imposed ceilings. We believe that understanding the kinds of informational imperfections on which we have focused in this paper is essential to understanding credit rationing under these circumstances.

We have argued further that the mechanism by which and the extent to which monetary policy may affect the macro-economic equilibrium may differ when the economy is in a credit rationing regime and when it is not. Developing the appropriate specifications for testing the hypotheses advanced in this paper remains a task for future research. 
NOTES

1. The type of credit rationing with which we have been concerned should also be distinguished from the phenomena that for any borrower the interest rate charged is an increasing function of the amount borrowed. This would be true with full information, provided that as the individual borrows more, the likelihood of default increases. It is also true if the \{interest rate, loan size\} schedule serves as a self-selection device. Our theory attempted to explain why some individuals could not borrow funds at any interest rate, though similar individuals seemed to have access to funds.

2. More generally, we can write income as a function of $R$ a $\mathrm{Y}=\max \{W+\mathrm{R}-(1+r), W-C\}$.

3. Recall that $Y_{0}$ is independent of technique, while $Y_{1}{ }^{r}>Y_{1} s$.

4. Formally, at the switch line, the choice of technique is undefined (the individual is indifferent as to which technique he employs). Accordingly, we could have assumed that on the switch line the borrower is undertaking the safe project with some probability. For each point on the switch line there is some probability of undertaking the safe project, such that the expected return to the bank is $\bar{v}$.

In this sense, then, the iso-return curve to the bank, though peculiarly shaped, is not discontinuous. It follows the switch line connecting the straight lines in Figure 3.

5. $\left(\frac{\mathrm{dr}}{\partial \mathrm{C}}\right)_{\bar{v}}=\frac{-\left(1-\mathrm{p}^{\mathrm{i}}\right)}{\mathrm{p}^{\mathrm{i}}}$

which is always less than the slope of the indifference curve given by (2) for $\mathrm{Y}_{1}>\mathrm{Y}_{0}$ and $\mathrm{U}^{\prime \prime}<0$.

6 There are two possible forms competitive contracts may take. One entails negative collateral, so long as the borrower risks some of this own or zero collateral, when the bank provides all the capital for the project. In this contract the bank is acting effectively as insurance agent.

The other entails positive collateral. These contracts entail a collateral requirement and an interest rate such that the individual is just indifferent between using the risky and the safe technique, i.e. it must be on the switch line. In the subsequent discussion, we focus on the latter contracts.

7. Using (3), we note that while for the rich, (1-p)/p is higher, $\mathrm{U}_{0}^{\prime} / \mathrm{U}_{1}^{\prime}$ may be smaller.

8. To focus on the incentive effects of contracts we assume that $\nu_{0}(G)>p^{r} R^{r}$ and $\nu_{1}(F)>p^{r} R^{r}$, so that banks prefer to make safe 
loans at either $F$ or $G$ to risky loans at contracts in which the banks gets all the returns.

9. Obviously, if the interest rate at $G$ is greater than at $F$ (or not much less) then bank profits at $G$ exceed those at $F$. Increases in the collaterizable wealth of the rich have two effects: the switch line is shifted down, which decreases the bank's profits; while the direct effect of more collateral serves to increase the bank's profits. The net effect is ambiguous, and depends on the extent to which (absolute) risk aversion decreases with wealth and the relative differences between the collateralizable and non-collateralizable wealth of the rich and poor. If there is constant absolute risk aversion, then the switch lines would coincide; by continuity, with slightly decreasing absolute risk aversion, the bank's return at G always exceeds that at $F$, but the converse will be true if there is strongly decreasing absolute risk aversion, and the difference in non-collateralizable wealth between the rich and poor borrowers is large.

10. In the case where the return to the loans to the poor exceeds the maximal return to the rich and where $L\left(\nu_{p}\{F\}\right)>N_{p}$ there may exists an equilibrium with rationing only of the rich. In this equilibrium, $i=\nu_{r}(G)$ and the rich are offered contract $G$. The poor are offered that contract along their switch line with the same expected return, as $G$ i.e. entailing lower $r$ and lower collateral than at

11. There may, of course, also be equilibria in which each bank offers several contracts. We do not investigate here equilibria in which banks offer several contracts.

12. We continue to assume a) $\nu\{G\}>p^{r} R^{r}$ and b) $\nu v\{f\rangle p^{r} R^{r}$. For most of our analysis only one of those inequalities is required. (Often only the weaker condition that $\nu_{1}(F)>p_{R} R^{r}$ is required; however, the exposition is simplified if we assume (a) and (b) hold throughout.) The reason inequalities (a) and (b) are required is that, if those inequalities were violated, banks might profitably offer contracts with interest rates $r=R^{t}-1$ and zero collateral that induce borrowers to use the risky technique. Because we are concerned with the incentive effects of contracts, extensive discussion of those cases would be tangential to the main focus of our analysis.

We also continue to assume for simplicity that the borrower risks none of his own capital, other than that demanded as collateral by the lender. But see below, Section 7 .

13. The contract set must include at least one contract which is preferred by the rich to $\{F\}$, for we have already shown that there is no contract which will increase bank returns given that $\mathbf{E}\left(\mathbf{U}^{\mathbf{r}}\right)=\mathbf{E}\left(\mathbf{U}^{\mathbf{r}}\{\mathbf{F}\}\right.$.

14. Note that we implicitly assume banks cannot commit themselves at the time they announce the set of contracts they offer to 
a particular allocation of funds or acceptance rate among the various contracts. This assumption seems natural since neither banks nor borrowers would be expected to know the out of equilibrium allocation of funds.

15. Formally, while the standard (Rothschild-Stiglitz) selection model can be formulated as a two stage game with the uninformed moving first, our model here is of a five stage game, the three extra stages are the acceptance by the bank (the uninformed) of the offers of the informed; the acceptances of the borrowers (the informed) of the offers of the bank (the uninformed), and the choice of a technique by the borrower.

16. The notion of reaction equilibrium was also discussed by RothschildStiglitz (1976). The concept of reaction equilibrium was criticised both for its ad hocery (the set of admissible reactions being arbitrarily specified), for its incompleteness (it being a dynamic concept within a static model), and for its inconsistency in spirit with competitive analysis. We analyzed the Nash equilibrium of a simple dynamic model, in which the "reactions" are fact derived.

17. The proof procedes, first by expressing the contract $\{G\}$ as a function of $C_{r}$ and $W_{r} \cdot$ Then $\nu_{1}\{F\}=\nu_{0}\{G\}$ and $\mathrm{EU}^{\mathrm{r}}\{G\}=\mathrm{EU}^{\mathrm{r}}\{\mathrm{F}\}$ can be viewed as defining implicit equations between $W_{r}$ and $C_{r}$. We evaluate the derivatives $\left(\mathrm{dW}_{\mathrm{r}} / \mathrm{dC} \mathrm{r}_{\mathrm{r}}\right)$ at $\left\{C_{p}, w_{p}\right\}$, and show that the equal return locus lies below the equal utility locus, and both loci have positive, finite slopes. For a proof, see J.E. Sitglitz and W. Weiss, "Credit Rationing with Collateral" Bell Core mimeo, August 26, 1985.

18. There is also a (trivial) separating equilibrium with rationing in which only contract $\{G\}$ is offered, and some, but not all, of the rich borrowers get loans at $\{G\}$. The poor borrowers would, of course, be unable to get loans.

19. In Stiglitz-Weiss [1981] we also argued, in the context of a simple two-period model, that reducing loan size may have strong adverse incentive effects.

20. We continue to assume that $L^{\prime}(i)>0$.

21. Of course, in practice, over the business cycle, this is likely to vary markedly as well, and whether in practice the extent of rationing increases or decreases in booms depends on the relative movements of the demand for funds and the supply. Either is, on a priori grounds, possible.

22. This assumes that the number of potential investor-borrowers remain unchanged. If there is a "balanced" increase in the supply of investors, then it is possible that the absolute number of $G$ loans would increase and indeed, even that the proportion of $G$ loans increases. The latter 
occurs if the increase in such borrowers is so large that $x$ falls even as the proportion of $G$ loans increases

$$
\text { Since } \quad x=\frac{N_{p}}{N-N_{G}}, \frac{d x}{x}=\frac{d N_{p}}{N_{p}}+\frac{d N_{G}}{N_{G}} \frac{N_{G}}{N-N_{G}}-\frac{d N}{N} \frac{N}{N-N_{G}} \text {, }
$$

$x$ can decrease even when $N_{G}$ increases,

23. From (10), if the absolute risk aversion of the rich and poor were

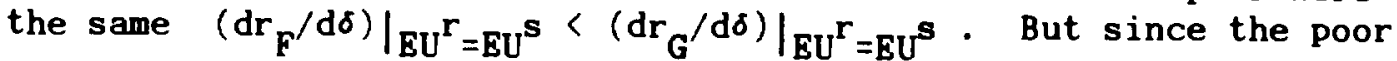

are more risk averse than the rich just the opposite may be true.

24. In our model, with no demand elasticity, a sufficiently large increase in productivity combined with a sufficiently large elasticity of supply of funds may eliminate credit rationing, provided $|d \delta / d \beta|$ is not too large.

25. This is particularly clear for the case of balanced changes on productivity, when interest rates do not change at all.

We can write the number (value) of loan applicants as a function of $\beta$ and $i$ : $N(i, \beta)$. Let $\eta_{\beta}^{N}$ be the elasticity of $N$ with respect to $\beta$, let $\eta_{i}^{N}$ be minus the elasticity of $N$ with respect to $i$ and $\eta_{i}^{L}$ be the elasticity of loan supply with respect to $i$. Then investment with perfect information will be less volatile if the percentage change in the equilibrium interest rate

$$
\frac{d \ln i}{d \ln \beta}=\frac{\eta_{\beta}^{N}}{\eta_{i}^{L}+\eta_{i}^{N}}
$$

is less than that with imperfect information. In the pooling equilibrium with balanced productivity changes,

$$
\frac{d \ln i}{d \ln \beta}=\frac{\dot{p}\left(1+r_{F}-C_{p}\right)}{\dot{p}\left(1+r_{F}-C_{p}\right)+C_{p}}
$$

This will be true if $C_{p}$ is small and $\eta_{\beta}^{N}$ is small, while both savings and investment are relatively interest inelastic.

26. For analytical purposes, we assume throughout this section that there are no changes in the set of available techniques.

27. This "dynamic" interpretation ignores the fact that the interest rate and 
income are determined simultaneously in the standard model.

28. Though in principle, the interest elasticity of different sectors may well differ, so that a given change in the interest rate would have a different impact on different sectors, the interest elasticity itself should be derived from the demand elasticities and production function of the different sectors; we doubt that the observed patterns of responses can be accounted for within the traditional models.

29. There are some grounds for believing that if the impact of monetary policy could be spread over more sectors-with the effect on each sector being reduced--then we would see smaller fluctuations in employment (but not necessarily in hours worked) in response to macroeconomic adjustments (see Baily [1979]).

30. Our model is thus consistent with the observation that in recessionary periods, monetary policy often seems to have little effect (because of the excess liquidity in the banking system at the time, monetary policy has little effect on the availability of credit; and since credit is not constrained, monetary policy can only attain its effects through the interest rate mechanism) while in other times, the imposition of a tight monetary policy seems to have large effects.

31. Obviously, this is not so true of small unincorporated businesses, but these account for a relatively small fraction of total investment.

32. Indeed, in our analysis, the inability of funds within the corporate sector to move easily from one firm to another--because of informational imperfections--is perhaps no less important than the difficulties of moving funds between the corporate and the household sectors.

33. Adam Smith, Wealth of Nations, 1776.

34. This includes not only the self-selection mechanism which have been the focus of this paper, but also auditing (direct examination).

35. We can show that if the first two conditions are satisfied, then there always exists some credit supply functions for which credit rationing will occur. 
Appendix

Comparative Statics Analysis of Effects of Changes in Supply of Loanable Funds

Case I.

Rich borrowers prefer contract $\{F\}$ to $\{G\}$, and $\nu(G)>\nu_{z}(F)$.

Let us suppose that initially there is an excess demand for credit (by rich borrowers) at contract $G: L(\nu(G))<N_{r}$. The equilibrium is then characterized by only contract $G$ being offered. (ii) Now let us consider an outward shift in the supply of loanable funds function so that $L(v(G))>N_{r}$. Banks will then compete for rich borrowers by moving the contract they offer rich borrowers southwest along the switch line of the rich borrowers. (For expositional simplicity, we restrict our analysis through the appendix to cases in which the high collateral contract requires more than $C_{p}$ of collateral.) This movement continues until a contract is reached such that $\nu(H)=\nu_{z}(F)$. (iii) suppose rich borrowers prefer contract $\{F\}$ to $\{H\}$. Then further outward movements in the supply of loanable funds function will cause contract $F$ to be offered;

the number of contract $F$ loans offered will be such that when all rejected rich borrowers get credit at contract $H$ the quantity of loans made is equal to $L(\nu(H))$. (iv) Further outward shifts in the loanable funds function will first eliminate rationing at contract $F$. There will then be a complete pooling equilibrium. Still further increases in supply will result in a southwest movement along the switch line of 
the poor borrowers. We denote this contract by $\hat{F}^{l}$ (v) If the utility function of borrowers is characterized by decreasing absolute risk aversion, the indifference curves of the rich borrowers become flatter as they become better off. Consequently, there may be a supply function of funds for which there exists a contract $H$ along the rich individual's switch line such that

$$
\nu_{z}(\hat{F})=\nu(\hat{H})
$$

and

$$
\left.\mathrm{EU}^{\mathrm{r}}(\hat{\mathrm{F}})\right)=\mathrm{EU}^{\mathrm{r}}(\hat{\mathrm{H}})
$$

the rich borrowers are indifferent between the high and low collateral contracts which would yield the same return to the bank.

At that point further outward movements in the supply of loanable funds function would be accompanied by some rich borrowers choosing high collateral contracts in preference to low collateral contracts. The greater is the proportion of rich borrowers choosing the high collateral contract, the greater is the proportion of poor borrowers among those choosing the low collateral contract, and consequently

1. We note the possibility that the indifference curve through $\hat{F}$ for the poor individuals may be flatter than that of the rich (at higher levels of collateral). In the standard RothschildStiglitz analysis, this pooling equilibrium could then be broken. In our model, however, a bank that of fered such a breaking contract would know that the other banks would recognize that the proportion of poor (safe) borrowers taking up their contracts would be less than $z$, and hence that their expected return would be less than $\nu_{F}(F)$. They would refuse to make loan offers. (It should be apparent that our model can be thought of as a formalization of what is sometimes called the Wilson-equilibrium). 
the higher is the return on that contract. The contract pairs, and choices of rich borrowers would then be such that rich borrowers are indifferent between the contract being chosen, and banks make the same return on the two contracts, i.e. the contract pairs will lie on the indifference curve of rich borrowers through the high collateral contract, and the ratio of rich borrowers choosing the high collateral contract in preference to the low collateral one will be such as to equate the return to a bank from the two contracts. ${ }^{2}$

Case II.

Rich borrowers prefer contract $\{G\}$ to contract $\{F\}, \nu(G)>\nu_{2}(F)$ and $L(\nu(G)<N$. Initially, only $G$ is offered. As the supply of funds function shifts outward, eliminating rationing, the contract being offered moves along the switch line of the rich borrowers until some contract $H$ is offered such that $\nu(H)=\nu_{1}(F)$.

Since the rich prefer $\{H\}$ to $\{G\}$ to $\{F\}$, they prefer $\{H\}$ to \{F\}; if contract $\{F\}$ is offered as well as contract $\{H\}$, contract \{F\} is only chosen by the poor borrowers. Further outward movements of the loan supply function would first cause an increase in the number of loans made at contract $F$, and then southwest movements of both the low and high collateral contracts along the switch lines of the poor and rich borrowers.

2. That is $\nu_{x}(\dot{F})=\nu(\hat{H})$ for $x \geq z$ and $\operatorname{EU}^{r}(\hat{F})=\operatorname{EU}^{r}(\hat{H})$. 
Case III.

Finally, let us consider the case where rich borrowers prefer contract $G$ to $F$ but $\nu_{z}(F)>v(G)$, and $L\left(\nu_{z}(F)\right)<N$. Then the equilibrium is characterized by only contract $F$ being offered. Starting at this equilibrium, outward shifts in the supply of loanable funds function first reduce and then eliminate rationing at $F$.

Further outward shifts cause banks to move the contract they offer southwest along the switch line of the poor borrowers until contract $F^{\prime}$ satisfying $\nu_{z}\left(F^{\prime}\right)=\nu(G)$ is reached. At that point, if the rich borrowers prefer $F^{\prime}$ to G, a single contract continues to be offered and outward shifts of the loan supply function continue to cause southwest movements of the contract along the switch line of the poor borrowers.

On the other hand, suppose the rich borrowers prefer $G$ to $F^{\prime}$. Consider a contract $F^{\prime \prime}$ along the poor's switch line, such that $\nu_{1}\left(F^{\prime \prime}\right)=\nu(G)$. If rich borrowers prefer $G$ to $F^{\prime \prime}$, then both contracts would be offered in equilibrium. All the rich borrowers choose $G$ and all the poor borrowers choose F". Further outward shifts in the loan supply function cause southwest movements of the two contracts along the switch lines of the poor and rich. At all points, the contracts generate the same return. Only poor borrowers choose the low collateral contract. Rich borrowers choose the the high collateral contract.

If the rich borrowers prefer $F^{\prime \prime}$ to $G$ then some contract $F *$ lying on the switch line of poor borrowers between $F^{\prime}$ and $F^{\prime \prime}$ is offered such that the rich borrowers are indifferent between this intermediate contract and contract G. In equilibrium, the proportion of rich borrowers choosing $G$ when offered $F *$ is such that the two contracts generate the same returns 
to banks. Further outward shifts in the supply of funds function would then cause southwest movements along the two switch lines. The contract pairs lie on the same indifference curve of the rich borrowers. The proportion of rich borrowers choosing the low collateral contract is such that the two contracts generate the same expected return to a bank. 


\section{REFERENCES}

Besanko, David and A. Thakor, "Competitive Equilibrium in the Credit Market Under Asymmetric Information," Northwestem University Discussion Paper, (1984)a.

Besanko, David and A. Thakor, "Collateral and Rationing: Sorting Equilibrium in Monopolistic and Competitive Markets," Northwestern University Discussion Paper, (1984)b.

Bester, Helmut, "Screening Versus Rationing in Credit Markets with Imperfect Information," American Economic Review, 75, (September 1985):850-855.

Bhattacharya, Sudipto, "Nondissipative Signaling Structures and Dividend Policy," Quarterly Journal of Economics ,95, (1980): 1-25.

Blinder, Alan, "Notes on the Comparative Statics is of a Stiglitz-Weiss Bank," unpublished mimeo, 1984.

Blinder, A. and J.E. Stiglitz, "Money, Credit Constraints and Economic Activity," American Economic Review, May 1983, pp. 297-302.

Diamond, Peter and J.E. Stiglitz, "Increases in Risk and in Risk Aversion," Journal Economic Theory, 14, (1977) 337-360.

Gale, Douglas and Martin Hellwig, "Incentive-Compatible Debt Contracts: The One Period Problem," Review of Economics Studies, 52, (October 1985): 647-664.

Guasch, J. Luis, and Andrew Weiss, "An Equilibrium Analysis of Wage - Productivity Gaps," Review of Economic Studies, 49 (1982): 485-497.

Guasch, J. Luis and Andrew Weiss, "Wages as Sorting Mechanisms in Competitive Markets with Asymmetric Information," Review of Economic Studies, 47, (1980): 149-165.

Greenwald, B. and J.E. Stiglitz, "Money, Imperfect Information, and Economic Fluctuations," in M. Kohn, ed., Taipei Symposium on Monetary Economics, Oxford University Press (forthcoming).

Greenwald, B. and J.E. Stiglitz, "Externalities in Economies with Imperfect Information and Incomplete Markets," Quarterly Journal of Economics, May, 1986: 229-264.

Greenwald, B., J.E. Stiglitz, and A. Weiss, "Information Imperfections in the Capital Markets and Macro-economics Fluctuations," American Economic Review, May 1984, Vol. 74, No.2, pp. 194-200. 
Kreps, David and Robert Wilson, "Sequential Equilibria" Econometrica, 50, (1982): 863-864.

Neary, P. and J.E. Stiglitz, "Expectations, Asset Accumulation and the Real- Balance Effect," presented at Dublin Meetings of the Econometric Society, September 1982.

Riley, John, "Competitive Signaling Reconsidered," U.C.L.A. Working Paper No. 294 (revised 1984).

Riley, John, "Information Equilibria," Econometrica, 47, (1979): 331-360.

Rothschild, Michael and J.E. Stiglitz, "Equilibrium in Competitive Insurance Markets," Quarterly Journal of Economics, 80, (1976): 629-649.

Shapiro, C. and J.E. Stiglitz, "Equilibrium Unemployment as a Worker Discipline Device," American Economic Review, June 1984, Vol. 74, No. 13, pp. 350-356.

Smith, Adam, The Wealth of Nations, Modern Library Edition, New York, Random House; 1937, first published 1776.

Stiglitz, J.E., "Information and Economic Analysis: A Perspective," Economic Journal Supplement, Vol. 95, Spring 1985, pp.21-42. (Paper presented at the Annual Conference of the Association of University Teachers of Economics, University of Bath, 1984).

Stiglitz, J.E., "Credit Markets and the Control of Capital," Journal of Money, Credit and Banking, May 1985 Vol. 17, No. 2, pp. 133-152.

Stiglitz, J.E., "Price Rigidities and Market Structure," American Economic Review, May 1984, Vol. 74, No. 1, pp. 350-356.

Stiglitz, J.E., "Ownership, Control and Efficient Markets: Some Paradoxes in the Theory of Capital Markets," in Economic Regulation: Essays in Honor of James R. Nelson, Kenneth Boyer and William Shepherd eds., (Ann Arbor, Michigan: Michigan State University Press, 1982, pp. 311-341).

Stiglit, J.E., "Prices and Queues as Screening Devices in Competitive Market," IMSS Technical Report No. 212, Stanford University, August 1976.

Stiglitz, J.E., "Some Aspects of the Pure Theory of Corporate Finance: Bankruptcies and Take-overs," Bell Journal of Economics and Management Science, Autumn 1972, pp.458-482.

Stiglitz, J.E. and A. Weiss, "Incentive Effects of Terminations: Applications to the Credit and Labor Markets," American Economic Review, 73, December (1983): 912-927. 
Stiglitz, J.E. and A. Weiss, "Credit Rationing and Collateral," Bell Communications Research Discussion Papers, 1985.

Stiglitz, J.E. and A. Weiss, "Credit Rationing in Markets with Imperfect Information," American Economic Review, June 1981, Vol. 71, No. 3, pp. 393-410.

Stiglitz, J.E. and A. Weiss, "Sorting out the Difference Between Screening and Signaling Models" Columbia University Discussion Paper 225 revised 1985.

Weiss, A., "Job Queues and Layoffs in Labor Markets with Flexible Wages," Journal of Political Economy, 1908, 88, pp. 526-538.

Wette, Hildegaard, "Collateral in Credit Rationing in Markets with Imperfect Information," American Economic Review, 73, (1983): 442-445.

Wilson, Charles, "A Model of Insurance Markets with Incomplete Information," Journal of Economic Theory, 16, 167-207. 
</ref_section> 


\section{Indifference Curves}

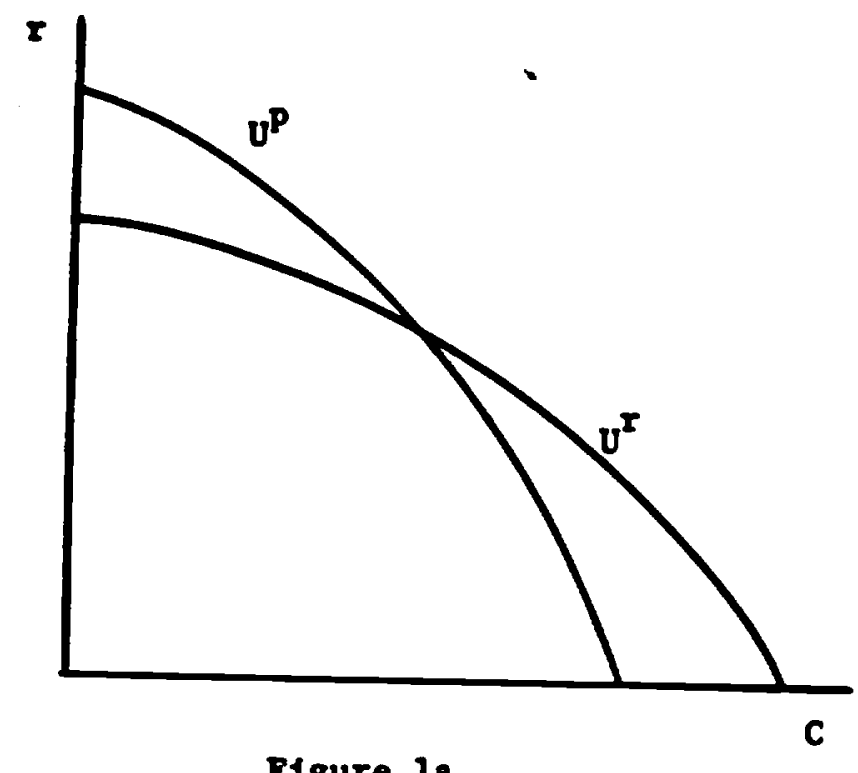

With alngle activity, Indifference curves are downard eloping and comvex.

A rich Individual has a flatter Indifference curve than a poorer Individual; he requires a greater reduction in the interest rate to compensate him for an Increase in collateral.

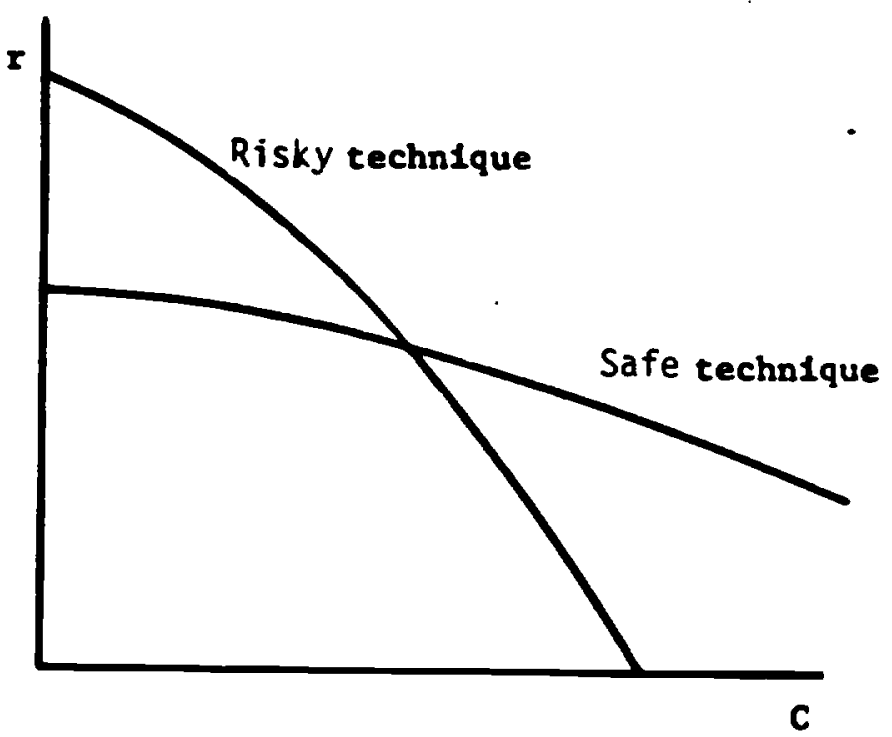

Figure 1b

Similarly, of two individuals with the same wealth, the one with the riskier technique has a steeper indifference curve. 


\section{Switch Lines}

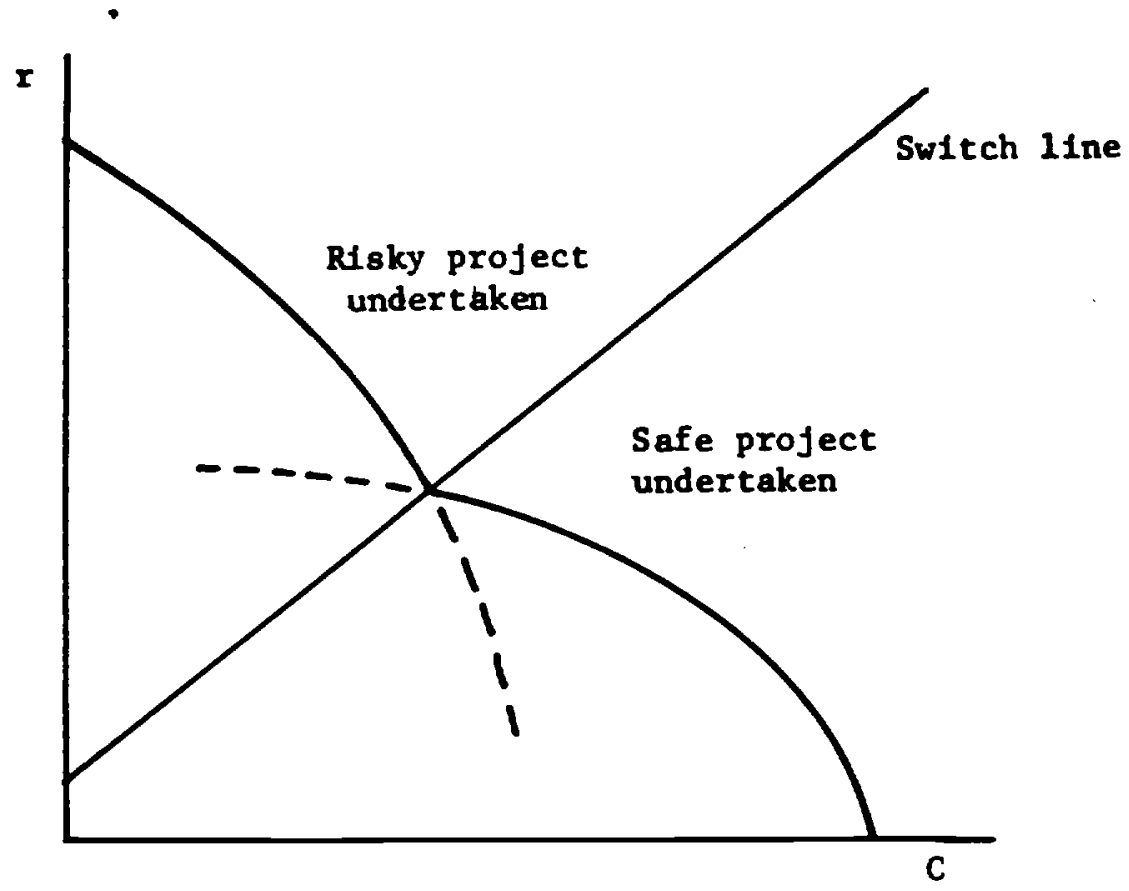

Figure 2a

The switch line gives those \{interest rate, collateral\} pairs at which the individual is indifferent between undertaking the safe and risky projects. It is upward sloping.

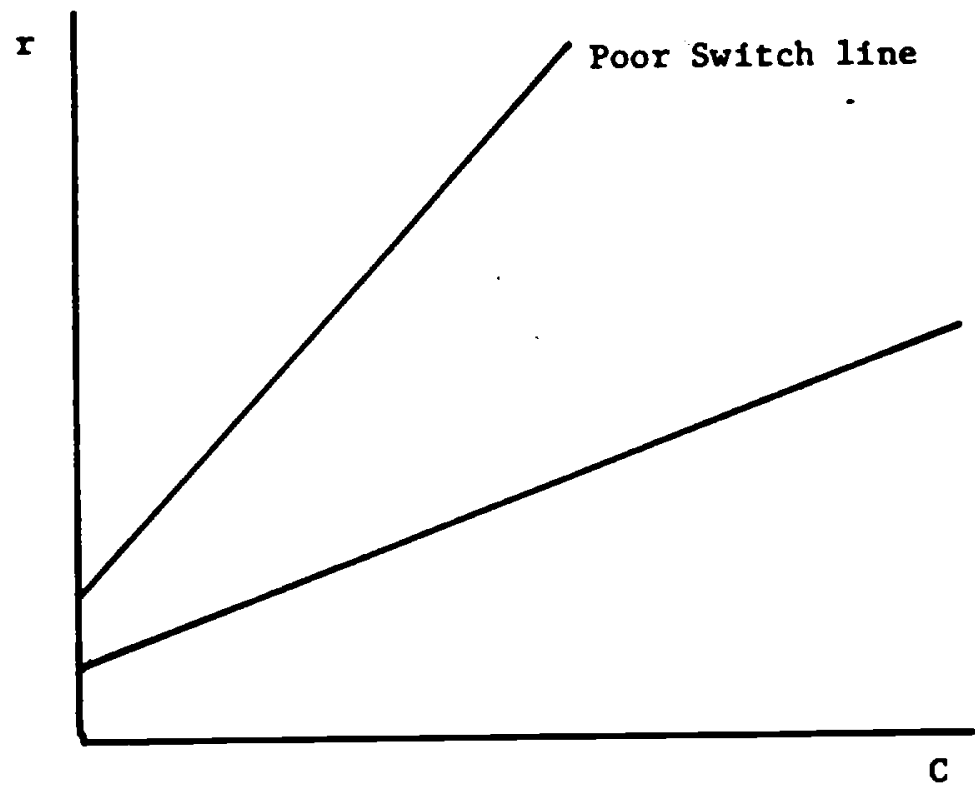

Rich Switch line

F1gure 2b

The Switch line of the poor lies above that of the rich. 


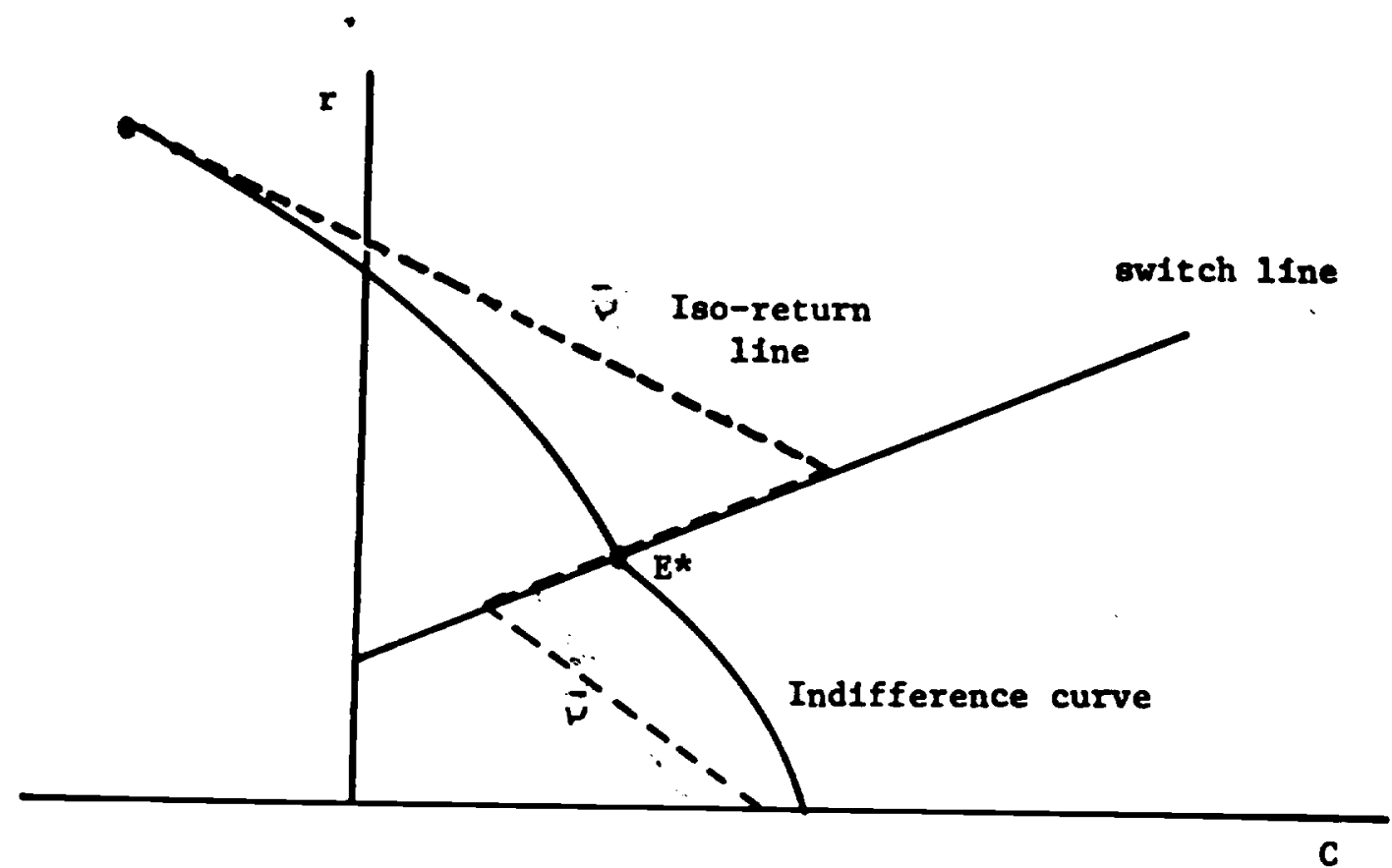

F1gure 3a,

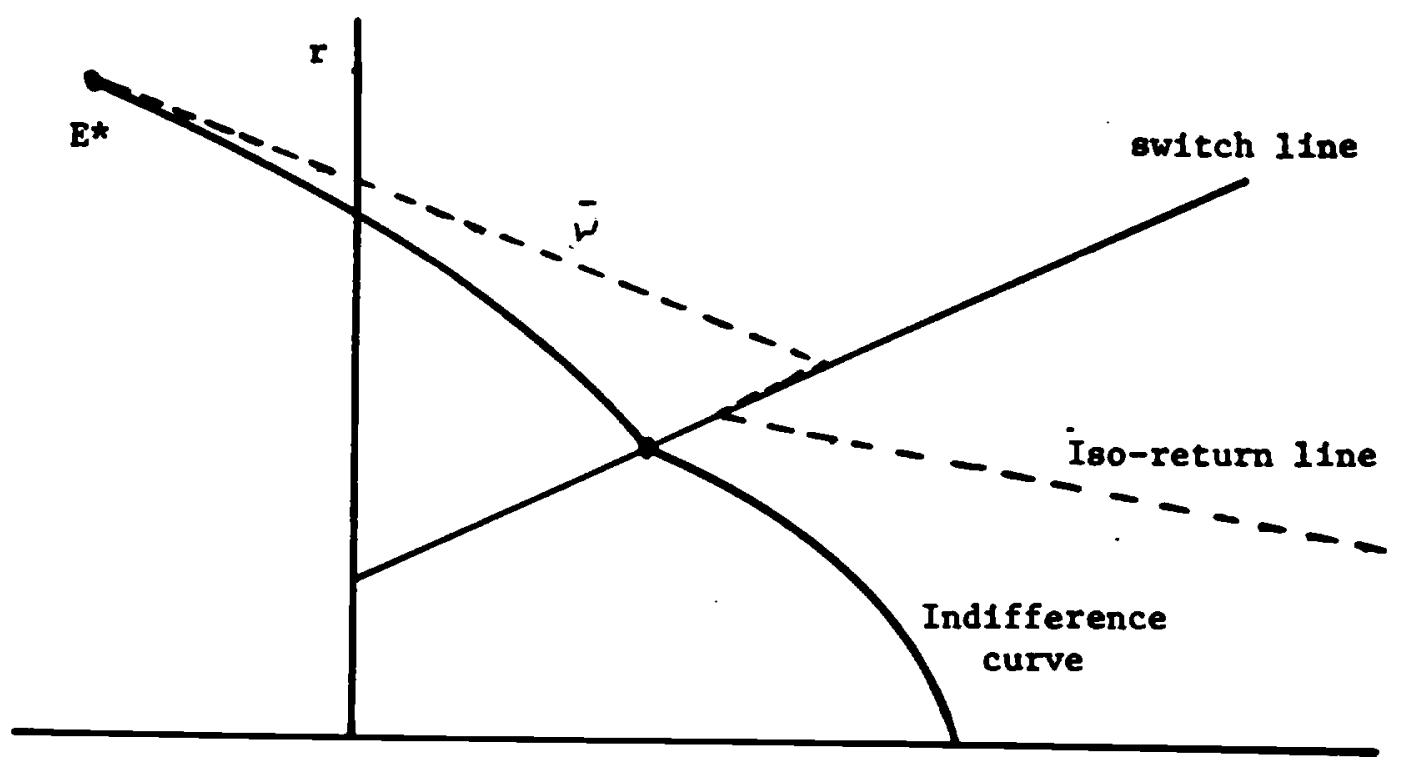

F1gure 3b

CONTRACTS WITH ONLY MORAL HAZARD

The bank elther provides Insurance (negative or zero collateral) as in $3 b$, or requires sufficlent collateral to Induce the borrower to undertake the safe project (3a). 


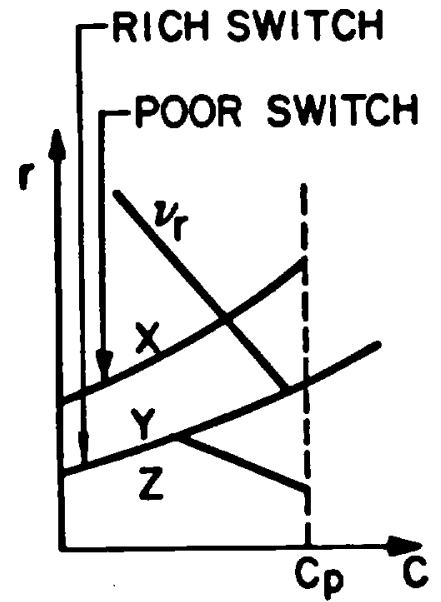

ISO-PROFIT LINE FOR

LOANS TO RICH
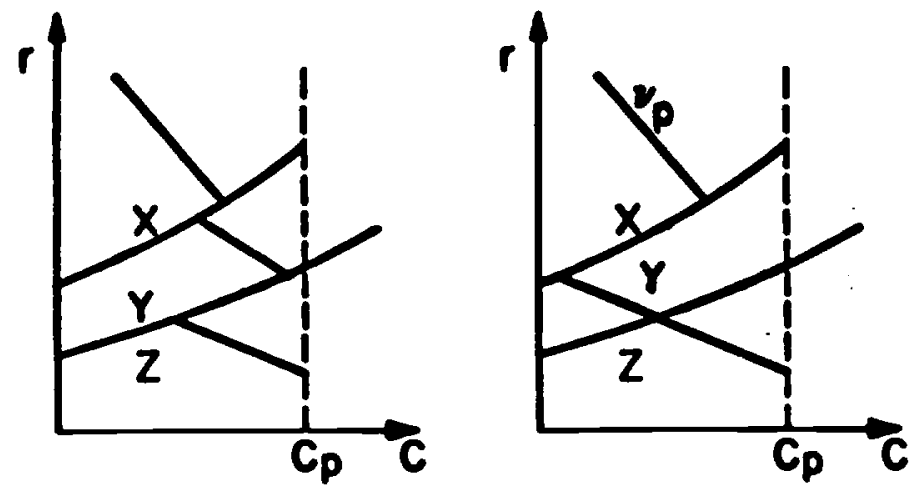

ISO-PROFIT LINE FOR ISO-PROFIT LINE FOR LOANS TO WHOLE POPULATION
LOANS TOPOOR

Figure 


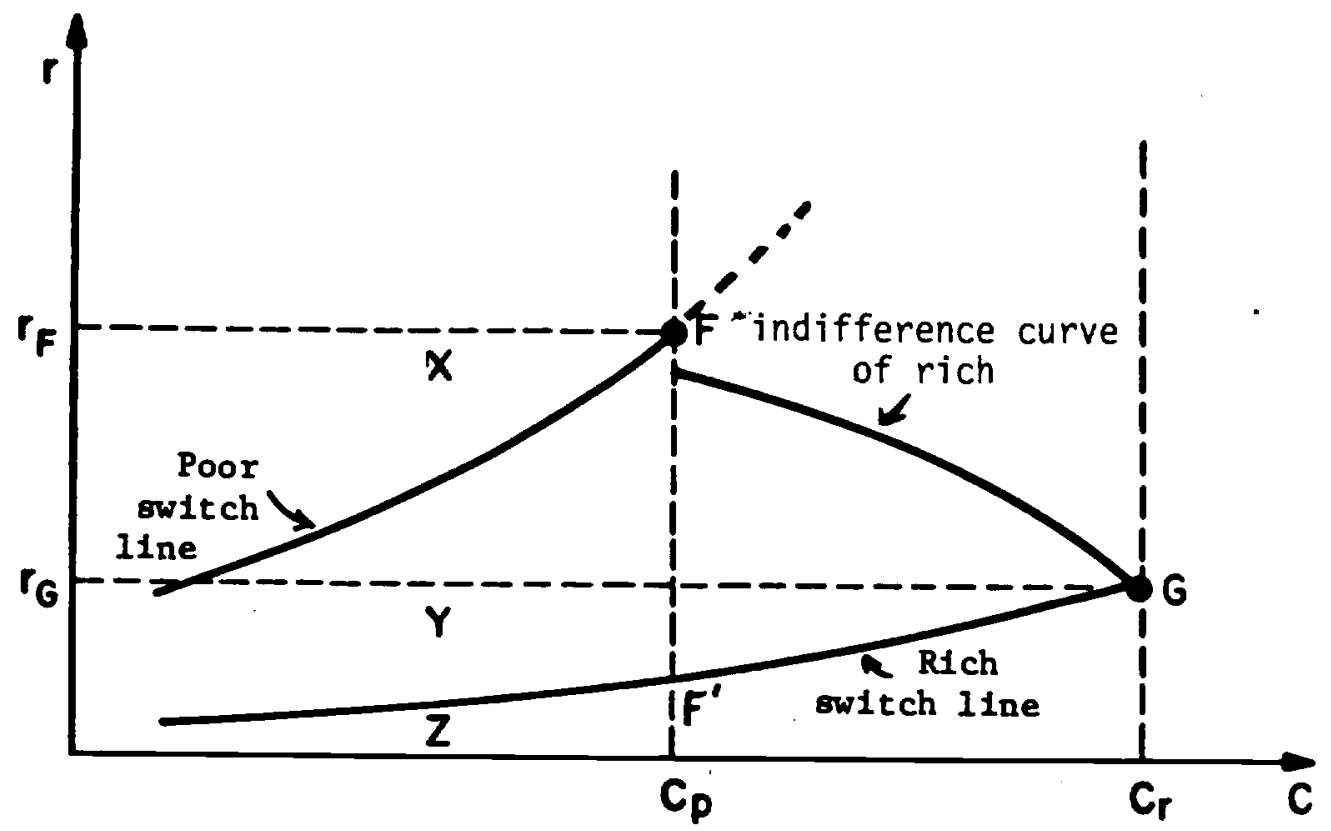

F1gure 5

F is the optimal contract to the poor $G$ is the optimal contract to the rich If there exists a pooling equilibriun, it must lie at $F$. 


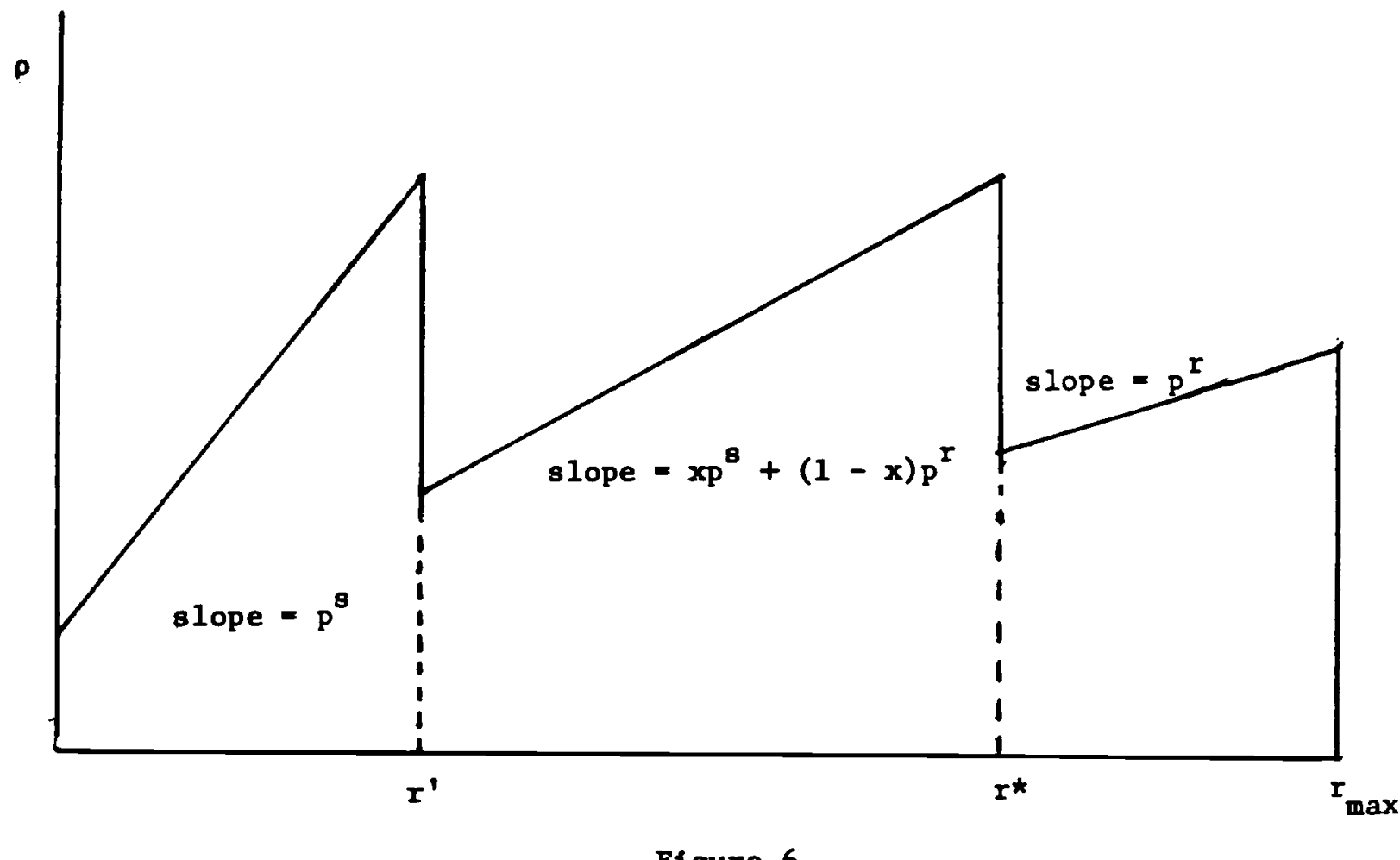

Figure 6

Collateral fixed at $\mathrm{C}_{\mathrm{P}}$

At $r^{\prime}$, rich $8 w 1$ tch to rlsky project

At $r^{\star}$, poor switch to risky project

Above $r_{\max }$ no one borrows

$x=$ fraction of those borrowing at $C_{p}$ who are poor 


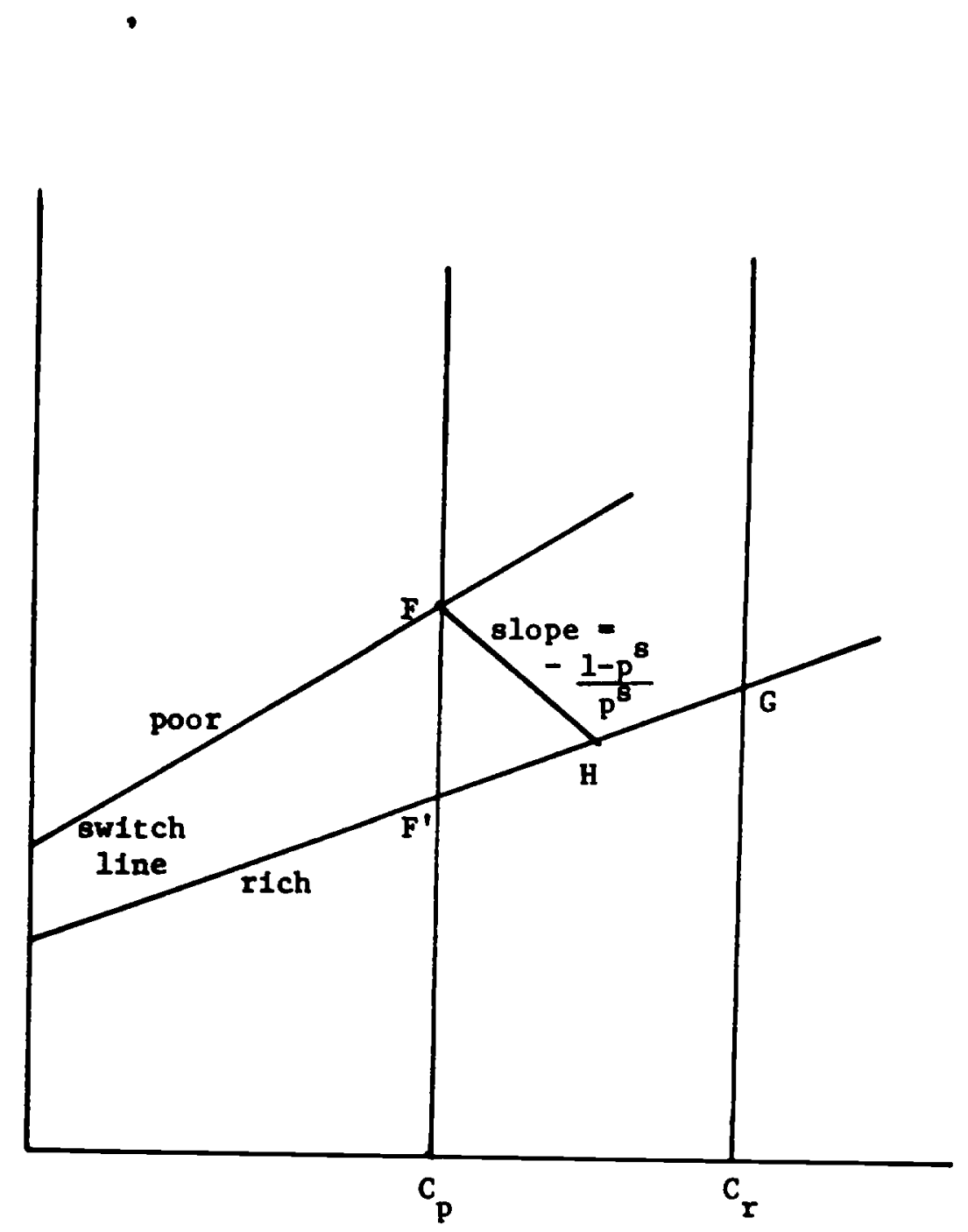

F1gure 7

Equilibrium with rationing of the poor (at F) but not the rich (who are offered contract $H$ ). 
F1gure 8

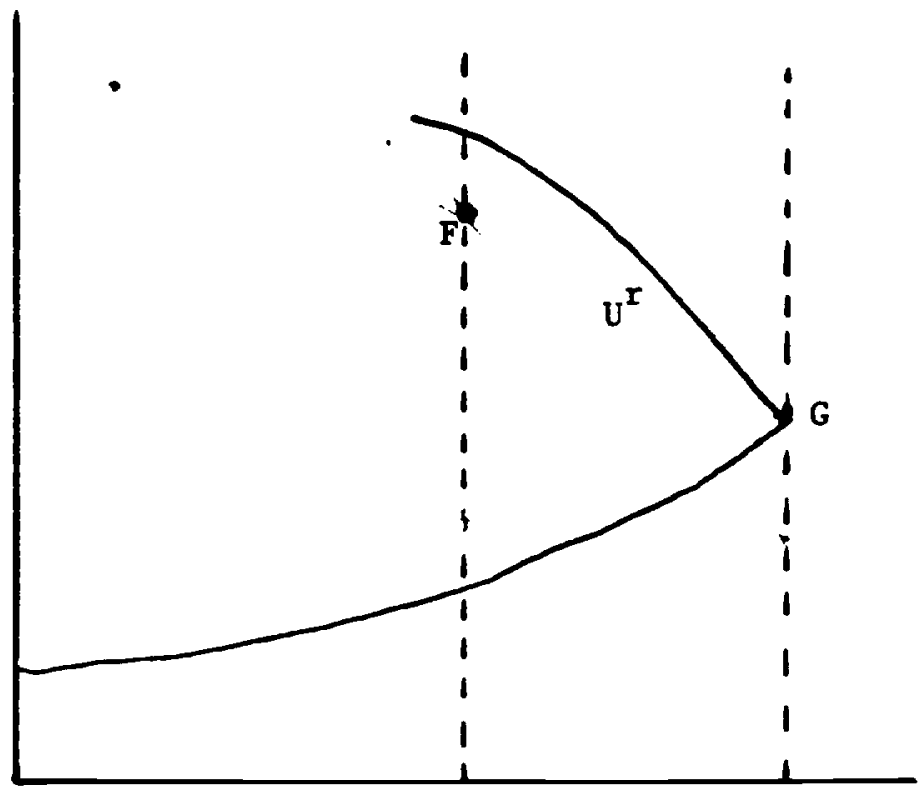

In Pooling Equilibrium, rich prefer F to G.

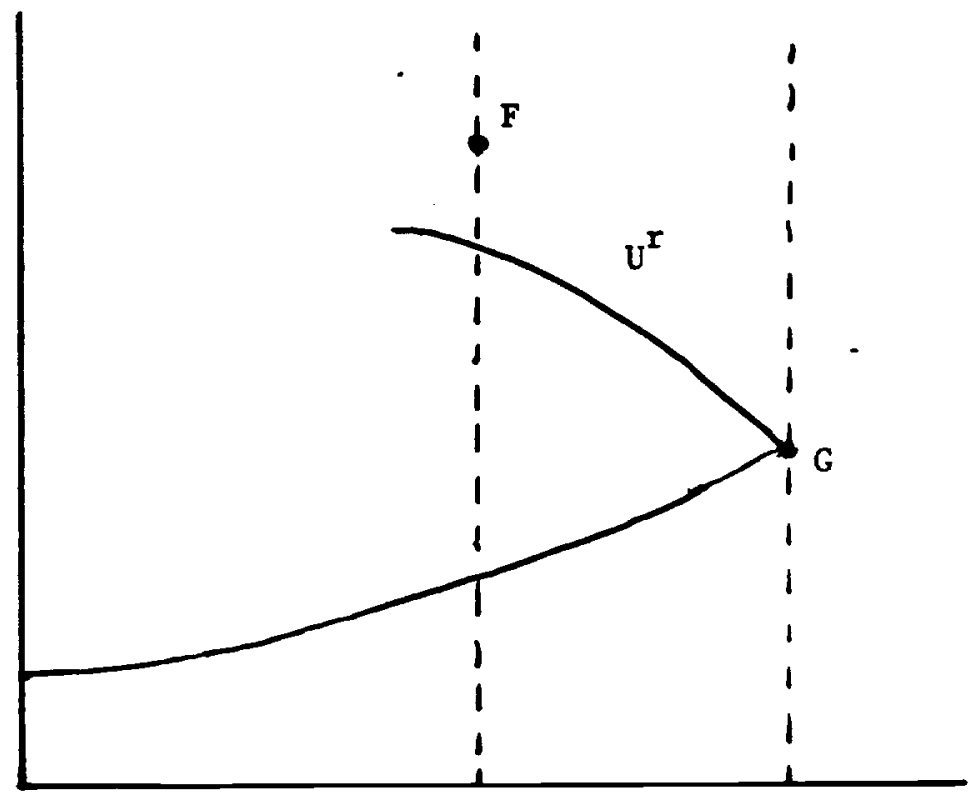

In partially separating equilibrium, rich prefer G to $F$. 


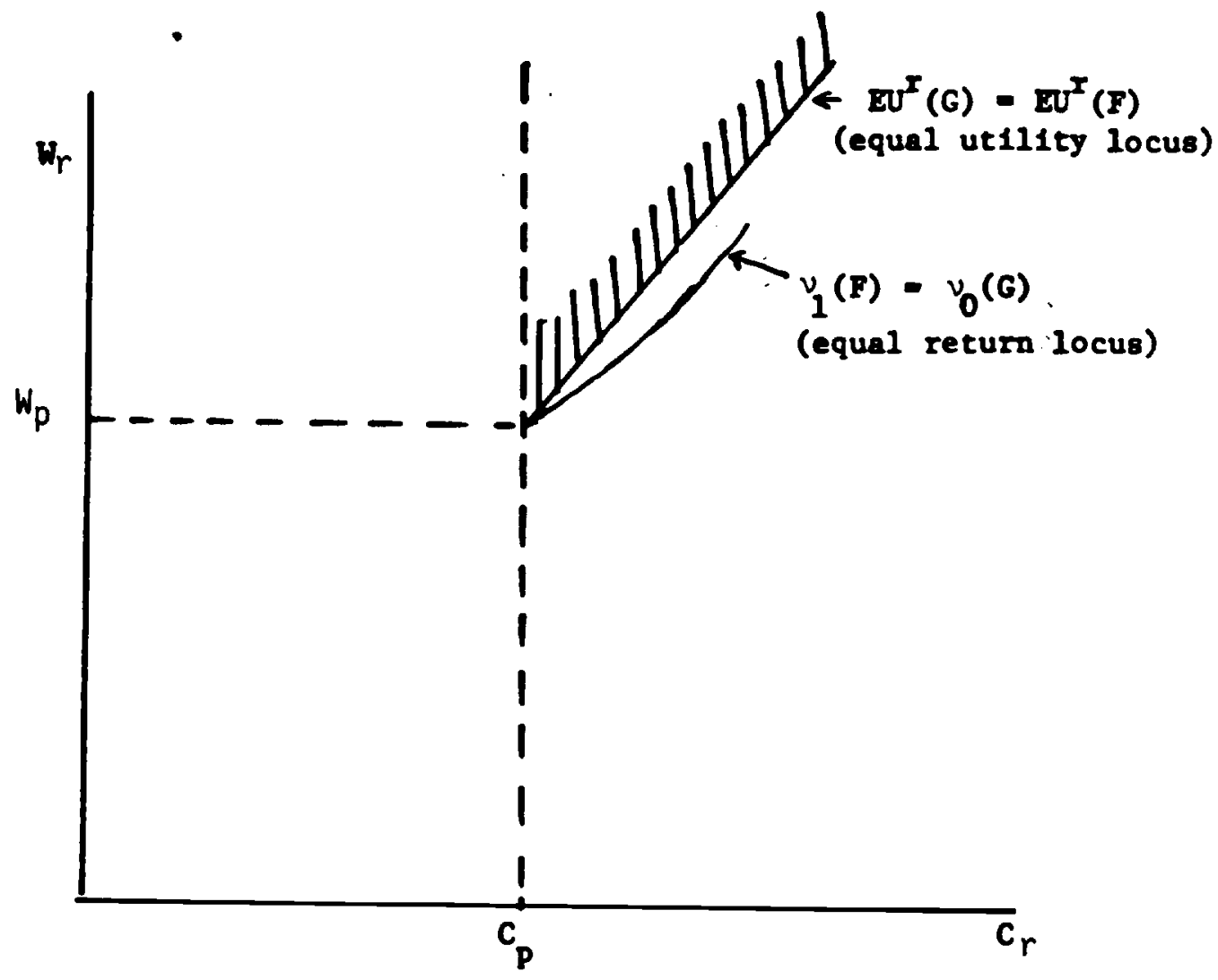

F1gure 9

Above equal utility locus, the rich prefer $G$ to $F$. Above the equal return locus, $v_{1}\{F\}>v\{G\}$. Near $\left\{C_{p}, w_{p}\right\}$, the equal return locus 11 es below the equal utility locus. The shaded area gives, for fixed collaterizable and non-collaterizable wealth of the poor, the set of collateralizable and noncollaterizable wealth levels of the ricb for which there must exist a partially separating equilibrium. 